\title{
Primary and secondary organic carbon downwind of Mexico City
}

\author{
X.-Y. Yu ${ }^{1}$, R. A. Cary $^{2}$, and N. S. Laulainen ${ }^{1}$ \\ ${ }^{1}$ Pacific Northwest National Laboratory, Richland, WA 99352, USA \\ ${ }^{2}$ Sunset Laboratory Inc., 10160 SW Nimbus Ave., Tigard, OR 97223, USA \\ Received: 7 October 2008 - Published in Atmos. Chem. Phys. Discuss.: 8 January 2009 \\ Revised: 12 August 2009 - Accepted: 26 August 2009 - Published: 18 September 2009
}

\begin{abstract}
In order to study particulate matter transport and transformation in the Megacity environment, fine particulate carbon was measured simultaneously at two supersites, suburban T1 and rural T2, downwind of Mexico City during the MILAGRO field campaign in March 2006. Organic carbon (OC), element carbon (EC), and total carbon $(\mathrm{TC}=\mathrm{OC}+\mathrm{EC})$ were determined in near real-time using a Sunset semicontinuous OCEC field analyzer. The semi-empirical EC tracer method was used to derive primary organic carbon (POC) and secondary organic carbon (SOC). Diurnal variations of primary and secondary carbon were observed at $\mathrm{T} 1$ and $\mathrm{T} 2$, which resulted from boundary layer inversion and impacted by local traffic patterns. The majority of organic carbon particles at $\mathrm{T} 1$ and $\mathrm{T} 2$ were secondary. The $\mathrm{SOC}_{\mathrm{TC}} \%$ $(\mathrm{SOC} \%=\mathrm{SOC} / \mathrm{TC} \times 100 \%)$ at $\mathrm{T} 1$ ranged from $0.5-93.8 \%$ with an average of $63.5 \pm 17.2 \%$. The $\mathrm{SOC}_{\mathrm{TC}} \%$ at $\mathrm{T} 2$ ranged from $9.3-98.1 \%$ with an average of $67.4 \pm 12.4 \%$. The average $\mathrm{EC}$ to $\mathrm{PM}_{2.5}$ percentage $\left(\mathrm{EC}_{\mathrm{PM}} \%=\mathrm{EC} / \mathrm{PM}_{2.5} \times 100 \%\right)$ and $\mathrm{OC}_{\mathrm{PM}} \%$ were $6.0 \%$ and $20.0 \%$ over the whole sampling time at $\mathrm{T} 1$. The $\mathrm{POC}$ to $\mathrm{PM}$ percentage $\left(\mathrm{POC}_{\mathrm{PM}} \%\right)$ and $\mathrm{SOC}_{\mathrm{PM}} \%$ were $3.7 \%$ and $16.3 \%$, respectively at the same site. The maximum $\mathrm{EC}_{\mathrm{PM}} \%$ was $21.2 \%$, and the maximum $\mathrm{OC}_{\mathrm{PM}} \%$ was $57.2 \%$ at $\mathrm{T} 1$. The maximum $\mathrm{POC}_{\mathrm{PM}} \%$ was $12.9 \%$, and the maximum $\mathrm{SOC}_{\mathrm{PM}} \%$ was $49.7 \%$ at $\mathrm{T} 1$. Comparison of SOC and POC at T1 and T2 showed similar characteristics under favorable meteorological conditions, which indicated that transport from $\mathrm{T} 1$ towards $\mathrm{T} 2$ took place. Strong correlations between EC and carbon monoxide (CO) and odd nitrogen species ( $\mathrm{NO}$ and $\mathrm{NO}_{\mathrm{x}}$ ) were observed at T1. This indicated that EC had nearby sources, such as local
\end{abstract}

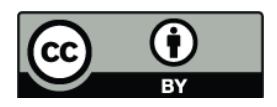

Correspondence to: X.-Y. Yu (xiaoying.yu@pnl.gov) traffic emissions. The $\mathrm{EC} / \mathrm{CO}$ ratio derived by linear regression analysis, with units of $\mu \mathrm{g} \mathrm{C} / \mathrm{m}^{3}$ and $\mu \mathrm{g} / \mathrm{m}^{3}$, respectively, was 0.004 at $\mathrm{T} 1$. Correlations were also seen between OC and $\mathrm{SOC}$ vs. the sum of oxidants, such as $\mathrm{O}_{3}$ and $\mathrm{NO}_{2}$, suggesting the secondary nature of carbons observed at $\mathrm{T} 1$.

\section{Introduction}

The Megacity Initiative: Local and Global Research Observations (MILAGRO) Campaign took place in Mexico City area and Veracruz in March 2006. It consisted of four simultaneous measurement campaigns, MCMA-2006 (The Mexico City Metropolitan Area - 2006 Experiment), MAXMex (The Megacity Aerosol Experiment), MIRAGE-Mex (Megacity Impacts on Regional and Global Environments), and INTEX-B (Intercontinental Chemical Transport Experiment - B); each had different objectives. The Pacific Northwest National Laboratory (PNNL) participated in the MAXMex and MIRAGE-Mex campaigns. Using Mexico City as the base of the field studies, as well as multiple platforms, the experiments focused on characterization of aerosol properties, formation, and transformation spatially in the outflow from the urban center. Three main ground sites, T0, T1, and $\mathrm{T} 2$, were selected to conduct the field campaign on the ground level. T0 was located at the Instituto Mexican del Petroleo at the city center. T1 was at the Universidad Technologica de Tecamac in Estado de Mexico, and T2 was at Rancho La Bisnaga near Tizayuca, Hidalgo.

This paper describes the characterization of particulate organic carbon (OC) and elemental carbon (EC) using the Sunset semi-continuous OCEC field analyzer at T1 and T2. Doran et al. (2007) reported on the evolution of aerosol optical

Published by Copernicus Publications on behalf of the European Geosciences Union. 


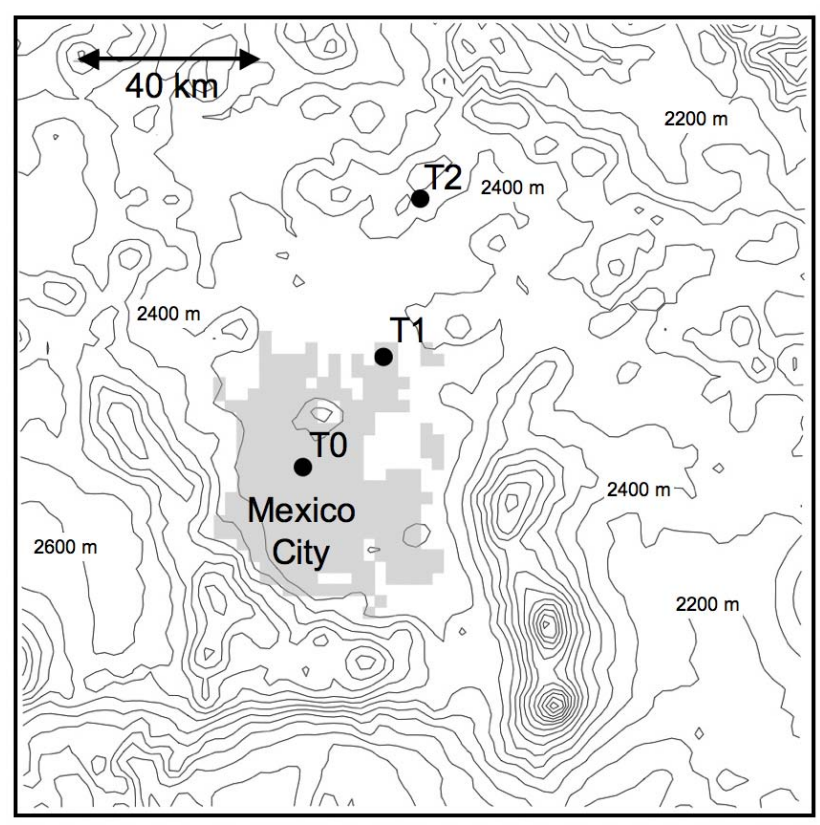

Fig. 1. Site map showing T0, T1, and T2 in relation to Mexico City.

properties derived from several particle measurements downwind of Mexico City. This paper differs from these recently published results of Doran et al. (2007), as its focus is on the chemical characteristics of carbon species at $\mathrm{T} 1$ and $\mathrm{T} 2$. Detailed analysis of primary organic carbon (POC) and secondary organic carbon (SOC) using the semi-empirical EC tracer method is summarized in this paper. Combined with meteorological findings (Fast et al., 2007; Shaw et al., 2007), we investigated potential emission sources of OC, EC, POC, and $\mathrm{SOC}$ at $\mathrm{T} 1$ and $\mathrm{T} 2$. Characteristics of carbon during $\mathrm{T} 1$ to $\mathrm{T} 2$ transport favorable and unfavorable days were studied. In addition, an effort was made to decipher the relationship between carbonaceous species such as OC, EC, POC, and SOC and other pollutants, including ozone $\left(\mathrm{O}_{3}\right)$, odd nitrogen species $\left(\mathrm{NO}_{\mathrm{x}}, \mathrm{NO}\right.$, and $\left.\mathrm{NO}_{2}\right)$, sulfur dioxide $\left(\mathrm{SO}_{2}\right)$, and carbon monoxide $(\mathrm{CO})$.

\section{Experimental}

\subsection{Field site description}

One of the main science drivers in the MILAGRO field design was to investigate evolution of trace gases and particulate matter from anthropogenic sources in Mexico City and their transport and effects on local and regional air quality and climate forcing. Three surface super sites, T0, T1, and $\mathrm{T} 2$, in the metropolitan Mexico City area were chosen during the MILAGRO campaign. The main idea was to sample pollutants following a Lagrangian flow when meteorological conditions were favorable downwind of Mexico City. Their relative location to each other and to other simultaneous observation sites is illustrated in Fig. 1. The T0 site, at the Instituto Mexicano De Petroleo (19.29'23.60 N, 99.0855.60 W, $2243 \mathrm{~m}$ ), was situated northwest of the basin on the central Mexican plateau. The T0 site was selected to capture fresh pollutants from the Mexico City. The T1 site, at the Tecamac University $(19.703 \mathrm{~N}, 98.982 \mathrm{~W}, 2270 \mathrm{~m})$, was about $50 \mathrm{~km}$ northeast from the T0 site. It was chosen to capture fresh and aged particles transported from $\mathrm{T} 0$ before leaving the metropolitan area. The T2 site, at Rancho la Bisnaga $(20.010 \mathrm{~N}, 98.906 \mathrm{~W}, 2542 \mathrm{~m})$, was about $35 \mathrm{~km}$ northeast of $\mathrm{T} 1$ at a higher elevation. It was chosen to measure aged pollutants from the Mexico City, in a non-urban area (Doran et al., 2007; Fast et al., 2007). The PNNL team conducted measurements at two surface sites, $\mathrm{T} 1$ and $\mathrm{T} 2$, during the MILAGRO campaign. Continuous sampling started on 9 March 2006 and ended on 30 March 2006.

\subsection{Instrumentation}

\subsubsection{Aerosol sampling stacks and inlets}

In order to eliminate interference from near ground activities, an aerosol sampling stack was used adjacent to the PNNL research trailer at the T1 and T2 sites, respectively. The sampling stack was made of PVC pipe $\sim 20 \mathrm{~cm}$ in diameter and extending $\sim 8 \mathrm{~m}$ above ground. The stack inlet was protected by a rain cap. A heated stainless steel sampling intake tube $(\sim 5 \mathrm{~cm}$ in diameter) was coaxially positioned in the center of stack $\sim 4 \mathrm{~m}$ below the top of the stack and extending through the lower end cap. The airflow through the aerosol sampling stack was $\sim 1000 \mathrm{lpm}$, of which approximately $120 \mathrm{lpm}$ was drawn into the heated tube. The tube was wrapped with heating tape and insulation and further encased in a PVC pipe. Electric power was applied to heat the sample line such that the relative humidity $(\mathrm{RH})$ of the sample air was maintained at or below $40 \%$. A sampling manifold containing four sampling ports was used to divide the sample flow into 4 streams of nominally $30 \mathrm{lpm}$ per line. One of the ports was used to supply the PNNL Sunset OCEC field analyzer. The other ports were used to supply other aerosol instruments.

\subsubsection{Sunset OCEC field analyzers}

Two semi-continuous Sunset OCEC analyzers (Model 3F, Sunset Laboratory Inc., Portland, OR) were used to measure OC and EC mass loadings at the T1 and T2 sites. Ambient samples were collected continuously by drawing a sample flow of $\sim 8 \mathrm{lpm}$. A cyclone was used upstream of the instruments to pass particles smaller than $2.5 \mu \mathrm{m}$. The airstream also passed through a denuder to remove any volatile organic compounds in the air. Sample flow rate was adjusted for the pressure difference between sea level and each of the sites to ensure accurate conversion of sample volume. During automated semi-continuous sampling, particulate matter was 
Table 1. The modified NIOSH 5040 thermal-optical protocol used during the MILAGRO campaign.

\begin{tabular}{lrr}
\hline Carrier Gas & Duration $(\mathrm{s})$ & Temperature $\left({ }^{\circ} \mathrm{C}\right)$ \\
\hline $\mathrm{He}-1$ & 10 & Ambient \\
$\mathrm{He}-2$ & 80 & 600 \\
$\mathrm{He}-3$ & 90 & 870 \\
$\mathrm{He}-4$ & 25 & No Heat \\
$\mathrm{O}_{2}-1$ & 30 & 600 \\
$\mathrm{O}_{2}-2$ & 30 & 700 \\
$\mathrm{O}_{2}-3$ & 35 & 760 \\
$\mathrm{O}_{2}-4$ & 105 & 870 \\
CalGas & 110 & No Heat \\
\hline
\end{tabular}

deposited on a quartz filter. The quartz filter was normally installed with a second backup filter, mostly to serve as support for the front filter. The portion of the sample tube containing the quartz filter was positioned within the central part of an oven, whose temperature was controlled by an instrument control and data logging program installed on a laptop computer and interfaced with the OCEC instrument.

After a sample was collected, in situ analysis was conducted by using the modified NIOSH method 5040, i.e. thermal optical transmittance analysis, to quantify OC and EC. The oven was first purged with helium after a sample was collected. The temperature inside the oven was ramped up in a step fashion to $870^{\circ} \mathrm{C}$ to thermally desorb the organic compounds. The pyrolysis products were converted to carbon dioxide $\left(\mathrm{CO}_{2}\right)$ by a redox reaction with manganese dioxide. The $\mathrm{CO}_{2}$ was quantified using a self-contained nondispersive infrared (NDIR) laser detection system. In order to quantify EC using the thermal method, a second temperature ramp was applied while purging the oven with a mixture containing oxygen and helium. During this stage, the elemental carbon was oxidized and the resulting $\mathrm{CO}_{2}$ was detected by the NDIR detection system. At the end of each analysis, a fixed volume of external standard containing methane $\left(\mathrm{CH}_{4}\right)$ was injected and thus a known carbon mass could be derived. The external calibration was used in each analysis to insure repeatable quantification. The modified NIOSH thermal-optical transmittance protocol used during MILAGRO is summarized in Table 1.

Errors induced by pyrolysis of OC are corrected by continuously monitoring the absorbance of a tunable diode laser beam $(\lambda=660 \mathrm{~nm})$ passing through the sample filter. When the laser absorbance reaches the background level before the initial temperature ramping, the split point between $\mathrm{OC}$ and EC can be determined. OC and EC determined in this manner are defined as Thermal OC and Thermal EC. Total carbon (TC) is the sum of Thermal OC and Thermal EC, $\mathrm{TC}=$ Thermal OC+Thermal EC, or TC=OC+EC. The Sunset OCEC analyzer also provides an optical measurement of EC
Table 2. Summary of linear least-squares fit parameters between quantities determined using optical and thermal-optical approaches.

\begin{tabular}{llll}
\hline Species & Optical vs. Thermal & $\mathrm{T} 1$ & $\mathrm{~T} 2$ \\
\hline EC & Slope & $0.93 \pm 0.01$ & $0.84 \pm 0.02$ \\
& $R^{2}$ & 0.95 & 0.37 \\
\hline OC & Slope & $1.43 \pm 0.01$ & $1.39 \pm 0.01$ \\
& $R^{2}$ & 0.96 & 0.91 \\
\hline
\end{tabular}

by laser transmission, i.e. Optical EC. Optical OC can be derived by subtracting Optical EC from total carbon, Optical $\mathrm{OC}=\mathrm{TC}-$ Optical EC, where TC is determined in the thermal analysis.

Filters were changed every few days before the laser correction factor reached $88 \%$. Hourly sampling was conducted at both $\mathrm{T} 1$ and $\mathrm{T} 2$ sites, i.e. 45-min ambient sampling followed by 15 min thermal-optical analysis. Daily, at midnight, a 0-min sampling blank was taken. These blanks were zero or below detection limits, therefore no additional blank subtraction was made. Both instruments were calibrated using an external filter with known OC and EC mass concentrations. Values reported were corrected to ambient temperature and pressure. Externally produced standard filters were also used to check the precision of the two instruments; the results of these tests were in excellent agreement. The relative standard deviations deduced from collocated in situ measurements between the two analyzers were $5.3 \%, 5.6 \%, 9.6 \%$, and $4.9 \%$ for Thermal OC, Optical OC, Optical EC, and TC, respectively. Details of these experiments are reported elsewhere (Bauer et al., 2009). The limits of detection for OC and $\mathrm{EC}$ determined using the thermal-optical method were estimated to be approximately $0.2 \mu \mathrm{g} \mathrm{C} / \mathrm{m}^{3}$ (Schauer et al., 2003). These values are consistent with subsequent tests with the two PNNL units after the MILAGRO campaign (Bauer et al., 2009).

Quantities directly determined using the thermal-optical protocol, namely Thermal OC and Thermal EC, are used in the following discussions. Thermal OC and thermal EC are usually referred to as OC and EC. Comparison between the thermally and optically determined observables showed good agreement at T1 and T2 during the MILAGRO campaign. Figure 2a depicts the scatter plots between Optical EC and Thermal EC at T1 and T2. Similarly, Fig. 2b depicts the scatter plots between Optical OC and Thermal OC at T1 and $\mathrm{T} 2$. Fitting parameter results using linear least-squares regression analysis are summarized in Table 2. Good linearity and consistency are observed for Optical EC and Thermal EC at T1, as well as Optical OC and Thermal OC at both sites. The higher scatter of Optical EC vs. Thermal EC at T2 results mostly from the much lower mass loading of elemental carbon at $\mathrm{T} 2$. 

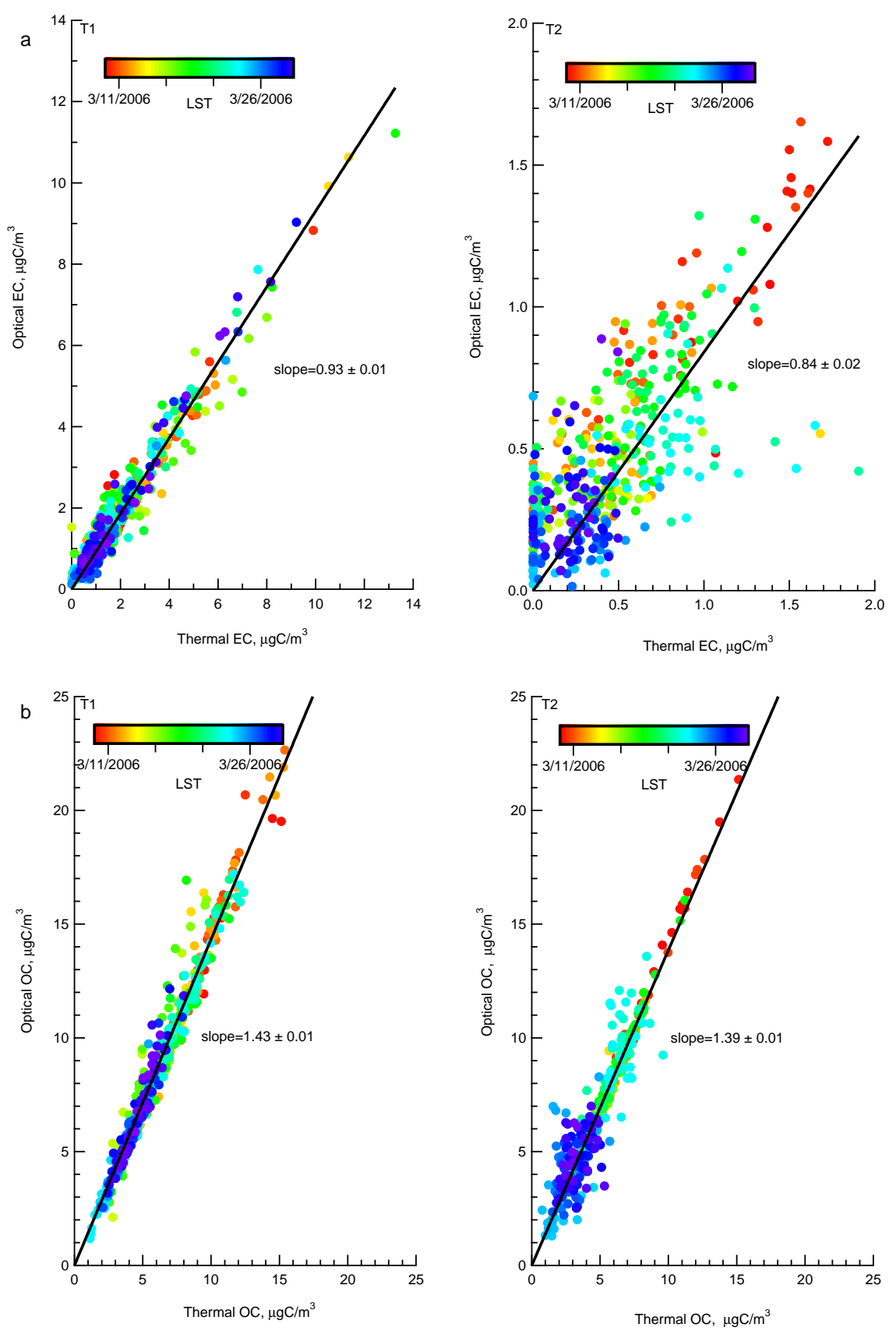

Fig. 2. (a) Scatter plots of Optical EC vs. Thermal EC at T1 (left panel) and T2 (right panel). The solids lines are linear least-squares fits. (b) Scatter plots of Optical OC vs. Thermal OC at T1 (left panel) and T2 (right panel). The solids lines are linear least-squares fits.

Results shown in this paper are produced using linear least-squares fit and Deming least-squares fit procedures. When dealing with regression analysis with two variables, Deming regression analysis is recommended (Cornbleet and Gochman, 1979; Martin, 2000). The latter is considered to represent data with higher accuracy than linear least-squares analysis, because it considers two variables instead of one. Linear least-squares regression tends to underestimate the slope when the error along the $\mathrm{x}$-axis is not considered.
Comparison between Deming regression analysis and linear least-squares analysis of the same data showed a difference less than 5\% for key fitting parameters (Bauer et al., 2009). This is true when data have good linearity. The photoacoustic absorption spectrometer (PAS), 3-wavelength nephelometer, particle soot absorption photometer were also deployed at T1. Discussion of these results, specifically of PAS, is detailed in Doran et al. (2007). 


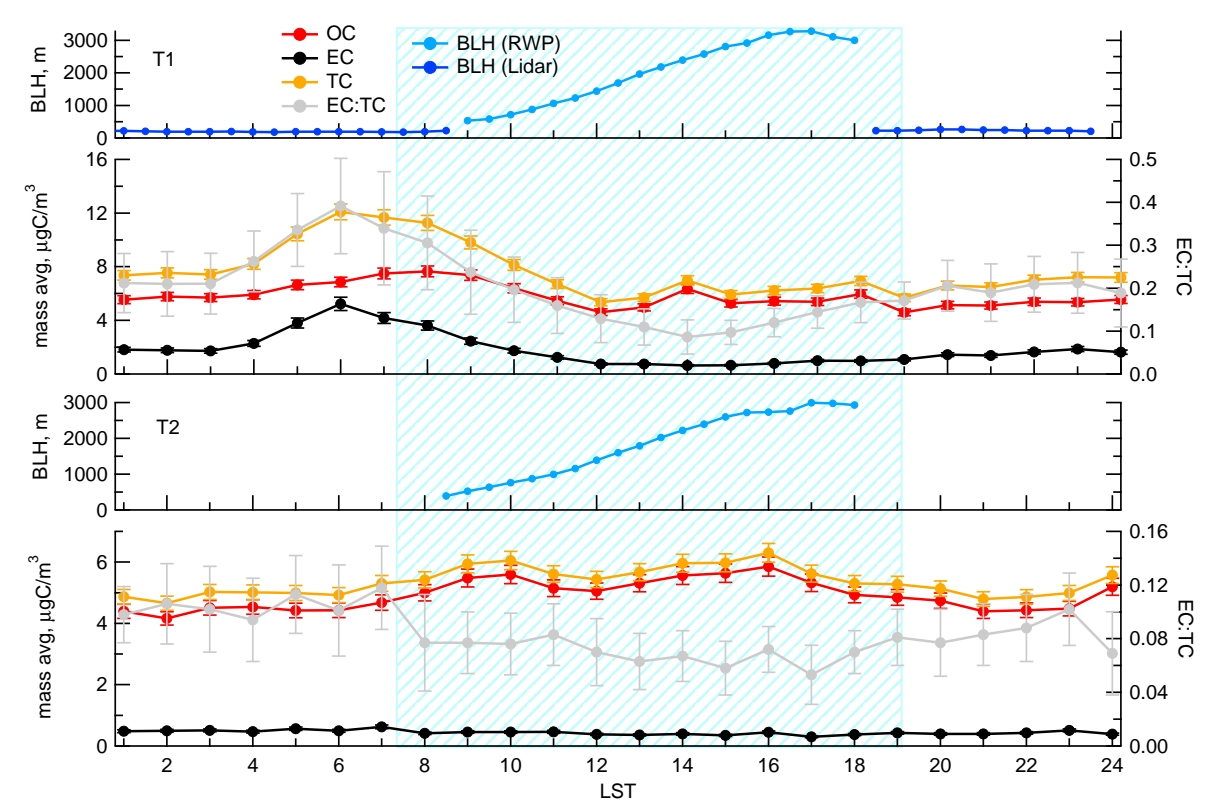

Fig. 3. Monthly average of Thermal EC, Thermal OC, and Thermal TC, shown on the left axis; and the ratios of Thermal EC: Thermal TC shown on the right axis. The top panel depicts data from T1, and the bottom panel depicts data from T2. Error bars are $\pm 1 \sigma$ from measurements. The average night period during the month of March in Mexico City is shaded in light blue.

\subsubsection{Meteorology measurements}

The boundary layer height was determined by the $915 \mathrm{MHz}$ radar wind profiler (RWP) operated by the Argonne National Laboratory. The boundary layer depth was determined by a lidar at night at T1. Only RWP measurements were available at T2. Details of instrument setup, data processing, and intercomparison are described elsewhere (Shaw et al., 2007). General meteorology measurements at $\mathrm{T} 1$ were provided by R. L. Coulter at Argonne National Laboratory and meteorology data from T2 were provided by our group at Pacific Northwest National Laboratory.

\subsubsection{Trace gas measurements}

Trace gases measurements including carbon monoxide (CO), ozone $\left(\mathrm{O}_{3}\right)$, sulfur dioxide $\left(\mathrm{SO}_{2}\right)$, and nitrogen oxides including nitric oxide $(\mathrm{NO})$, nitrogen dioxide $\left(\mathrm{NO}_{2}\right)$, and $\mathrm{NO}_{\mathrm{x}}$ $\left(\mathrm{NO}_{\mathrm{x}}=\mathrm{NO}+\mathrm{NO}_{2}\right)$ were provided by the research groups of L. G. Huey at the Georgia Institute of Technology and R. Cohen at the University of California, Berkeley. Details of instrument principles of operation and configuration are described elsewhere (Chen et al., 2005; Fehsenfeld et al., 1987; Nunnermacker et al., 1998). The non-volatile $\mathrm{PM}_{2.5}$ mass concentrations were determined using an R\&P Tapered Element Oscillating Microbalance (TEOM) monitor (Patashnick and Rupprecht, 1991). Time used in all measurements was often expressed in either local standard time (LST) or coordinated universal time (UTC). The difference between LST and UTC is $6 \mathrm{~h}$ in this experiment, UTC- $6 \mathrm{~h}=\mathrm{LST}$. For discussion purposes, we use only LST.

\subsubsection{The ToF AMS}

An Aerodyne Time-of Flight Aerosol Mass Spectrometer (ARI, c-ToF-AMS, Serial Number 40), manufactured by the Aerodyne Research, Inc., was used to measure the chemical composition of aerosols. Description of the operation principles of the c-ToF-AMS is detailed elsewhere (Drewnick et al., 2005). The size cut of the AMS is approximately $1 \mu \mathrm{m}$. The AMS used its own inlet, and it was calibrated several times during the campaign. The collection efficiency used to quantify mass loadings is 0.5 . The c-ToF-AMS was operational between 11 March 2006 and 30 March 2006, and it provided ensemble averages every $5 \mathrm{~min}$.

\section{Results and discussion}

\subsection{Overview of $\mathrm{OC}$ and $\mathrm{EC}$ at $\mathrm{T} 1$ and $\mathrm{T} 2$}

Simultaneous measurements of $\mathrm{OC}$ and $\mathrm{EC}$ at $\mathrm{T} 1$ and $\mathrm{T} 2$ revealed that the carbon composition at these two sites was quite different. Figure 3 depicts hourly-averaged Thermal OC, Thermal EC, TC, Thermal EC:TC ratio, and boundary layer height at $\mathrm{T} 1$ and $\mathrm{T} 2$ during the entire campaign. The day period during the month of March in Mexico City is shaded in light blue. Error bars are standard deviations of each observable. 

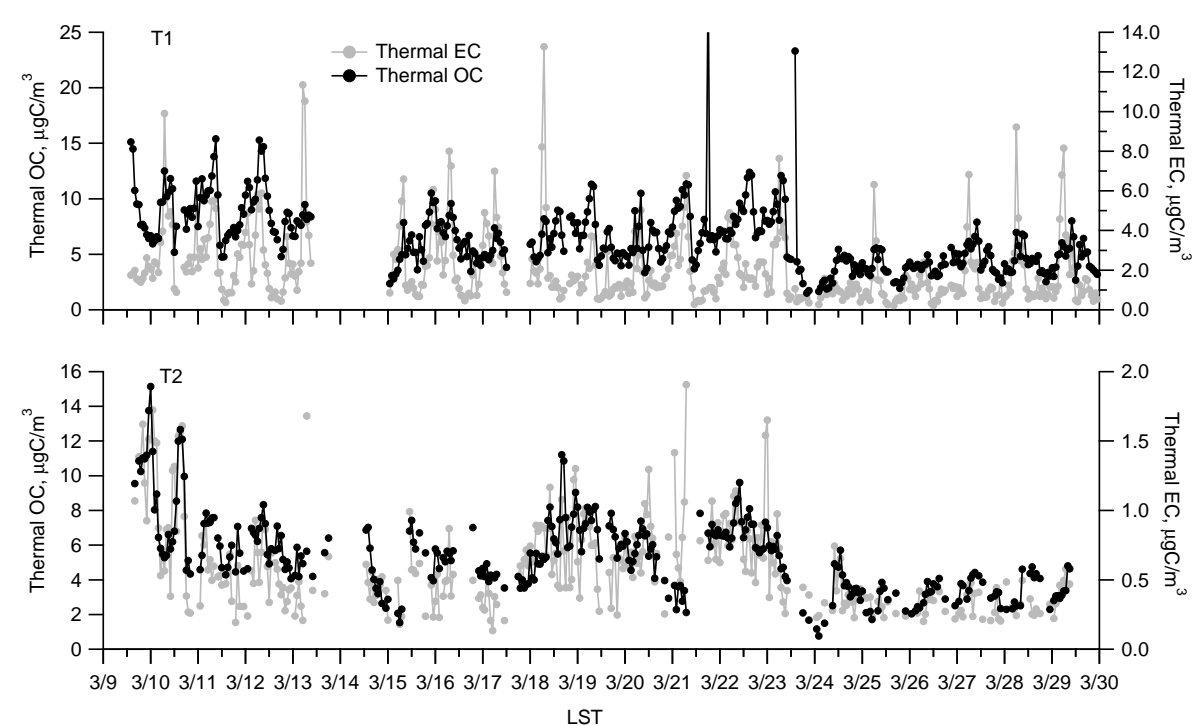

Fig. 4. Time series of Thermal OC (black dots) and Thermal EC (light grey dots) at T1 and T2 sites.

A distinctive diurnal pattern is observed for OC, EC, and $\mathrm{TC}$ at $\mathrm{T} 1$. $\mathrm{OC}$ arrived at the first maximum at 08:00 a.m. (LST) at T1. A second peak of OC occurred at 02:00 p.m. EC reached its first peak at 06:00 a.m. TC peaked first at 06:00 a.m., then at 02:00 p.m. during the early afternoon rush hour. The ratio of EC to TC (EC:TC) reached the first daily peak at 06:00 a.m. The background mass loading was approximately $\sim 1 \mu \mathrm{g} \mathrm{C} / \mathrm{m}^{3}$ for EC, $\sim 5 \mu \mathrm{g} \mathrm{C} / \mathrm{m}^{3}$ for OC, and $\sim 6 \mu \mathrm{g} \mathrm{C} / \mathrm{m}^{3}$ for TC, respectively, at $\mathrm{T} 1$.

The boundary layer height remained shallow at night and early morning until approximately 08:30 a.m. (LST). It then began to grow and reached its maximum of $\sim 3300 \mathrm{~m}$ above ground between 04:00-05:00 pm. Thus, it is not surprising to observe the pronounced growth of $\mathrm{EC}, \mathrm{OC}$, and consequently $\mathrm{TC}$ at $\mathrm{T} 1$ in the early morning before the boundary layer height started to increase. Since T1 was located near a busy local express way and chosen to be downwind of the center of Mexico City, it received both fresh local anthropogenic emissions, as well as transport from the city when the meteorological conditions were suitable. The daily EC peak at 06:00 a.m. was likely caused by local early morning traffic. The slightly delayed OC peak at 08:00 a.m. could be a result of processing of both fresh and aged particles. The boundary layer diluting effect on particle matter mass loadings was seen in EC, OC, and TC.

Unlike T1, EC, OC, TC, and EC:TC did not present as a distinctive diurnal pattern at $\mathrm{T} 2$. The baseline of $\mathrm{OC}$ stayed at $\sim 4 \mu \mathrm{g} \mathrm{C} / \mathrm{m}^{3}$ and the baseline of EC stayed at $\sim 0.4 \mu \mathrm{g} \mathrm{C} / \mathrm{m}^{3}$ at T2. The OC mass loading started to grow at 08:00 a.m. almost simultaneously as the boundary layer started to grow deeper. OC first peaked at T2 at 10:00 a.m. (LST), it then reached its second maximum at $03.00 \mathrm{p} . \mathrm{m}$. The growing boundary layer had the dilution effect which could explain partially why a higher mass loading peak was not observed later in the day at T2. A third OC peak occurred at midnight. The first daytime OC maximum at T2 was about two hours later than seen at T1. Although EC mass loadings generally remained much lower at $\mathrm{T} 2$ than at $\mathrm{T} 1$, they peaked at 07:00 a.m. and 04:00 p.m. during day-time. A local maximum occurred at night 11:00 p.m. after sunset. TC reached its first maximum after sunrise at 10:00 a.m., its second peak at 04:00 p.m., and its third peak at midnight. The EC:TC peaked at 07:00 a.m. after sunrise. After sunset, EC:TC peaked at 11:00 p.m. The EC:TC dipped at midnight, this was largely due to the local maximum of TC and the flat EC at the same hour. Since T2 was at a ranch in the middle of a hill far removed from busy interstate express ways and local traffic, it seemed that it was less affected by local anthropogenic emissions compared with $\mathrm{T} 1$ implied by the less pronounced diurnal pattern at $\mathrm{T} 2$.

\subsection{Particulate $\mathrm{OC}$ and $\mathrm{EC}$ time series at $\mathrm{T} 1$ and $\mathrm{T} 2$}

Time series of $\mathrm{OC}$ and $\mathrm{EC}$ at $\mathrm{T} 1$ and $\mathrm{T} 2$ are depicted in Fig. 4. Significant reduction of mass loadings was observed on 24 March 2006, when rain occurred at both sites. Periods of rain were observed during the afternoon for the rest of the campaign. The last week of rain in fact formed a nice contrast with observations from the beginning of the campaign, when dry and warm weather persisted in the area. The time series of EC:TC from both sites are plotted in Fig. 5a. Statistics of mass loadings of EC, OC and TC, as well as EC:TC at $\mathrm{T} 1$ and $\mathrm{T} 2$ are summarized in Table 3 . These results at $\mathrm{T} 1$ are comparable with measurements obtained by another Sunset OCEC analyzer located at the same site (Hennigan et al., 2008; Stone et al., 2008). The statistics of OC and EC 

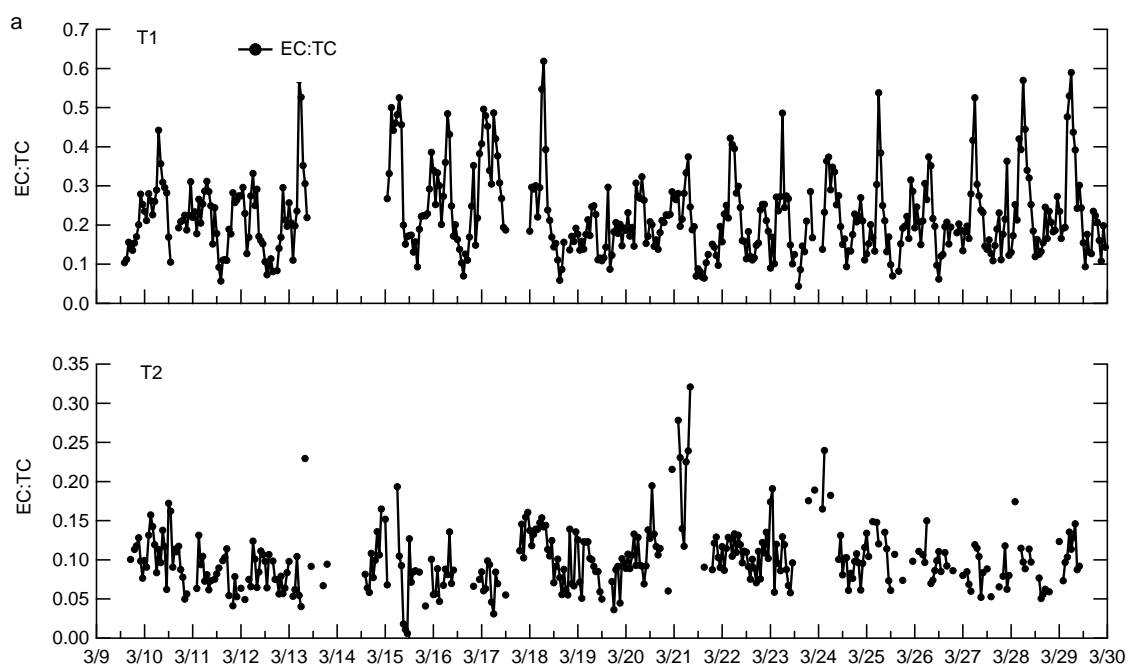

LST
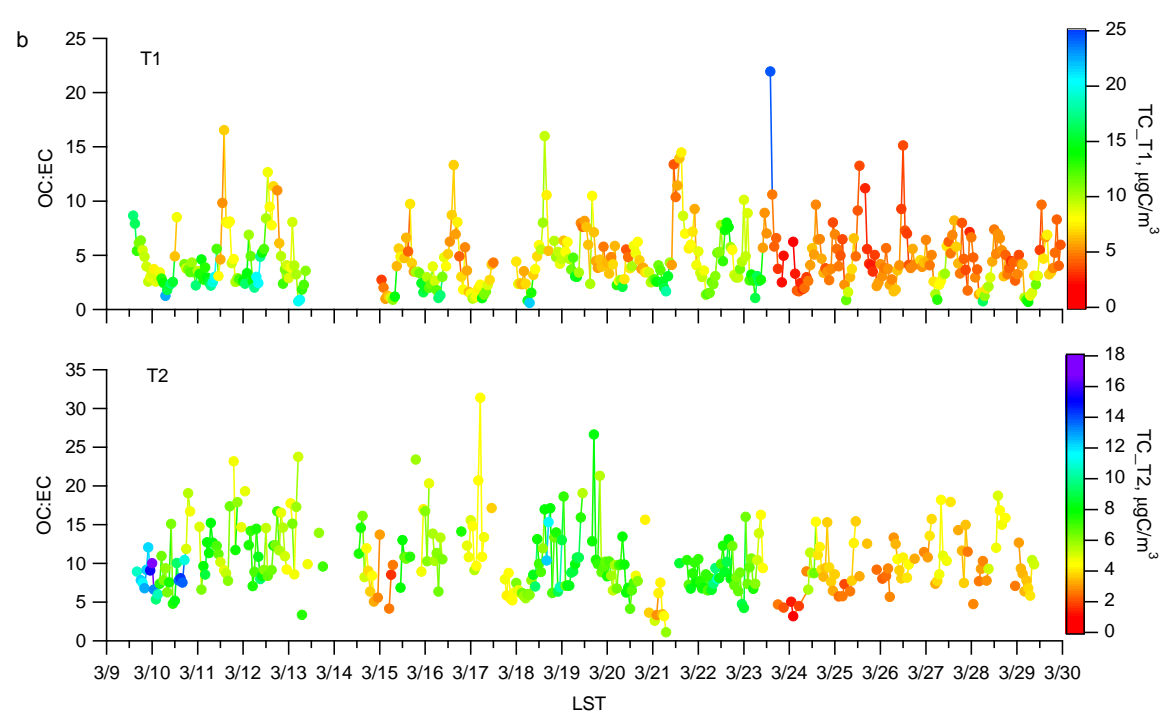

Fig. 5. (a)Time series of the ratios of Thermal EC to TC. (b) Time series of the ratios of Thermal OC to Thermal EC at T1 and T2. The data are shaded as a function of TC mass loading at each site.

measurements for two weeks in March 2006 was reported in the latter. Significantly higher EC was observed at T1 than at $\mathrm{T} 2$. Although the average mass loadings of $\mathrm{OC}$ were fairly comparable between $\mathrm{T} 1$ and $\mathrm{T} 2$, the dynamic range was much wider at T1 than T2. The OC peaked at $29.3 \mu \mathrm{g} \mathrm{C} / \mathrm{m}^{3}$ on 22 March 2006; and the minimum value of $1.5 \mu \mathrm{g} \mathrm{C} / \mathrm{m}^{3}$ occurred on 24 March 2006 at T1. The highest OC occurred on 10 March 2006; and the lowest on 24 March 2006 at T2.

\subsection{The $\mathrm{OC}$ to $\mathrm{EC}$ ratios at $\mathrm{T} 1$ and $\mathrm{T} 2$}

Another approach to evaluate OC and EC data was to look at the ratio of OC to EC (OC:EC) which gave indication of secondary and primary organic carbon at specific locations
(Lim and Turpin, 2002; Turpin and Huntzicker, 1991; Turpin et al., 1991). The time series of OC:EC is shown in Fig. 5b. The data points are colored as a function of TC mass loadings at each site. High TC mass loadings do not necessarily correspond to high OC:EC ratios at both sites. The majority of OC:EC values at T1 are in the range of $1-10$, with TC in the range of $1.9-29.3 \mu \mathrm{g} \mathrm{C} / \mathrm{m}^{3}$. On the other hand, OC:EC values at T2 are mostly in the range of 5-20, with TC in the range of $1.0-16.7 \mu \mathrm{g} \mathrm{C} / \mathrm{m}^{3}$. The EC:TC sometimes is used as an indicator of primary vs. secondary organic aerosols. The higher OC:EC values at T2 than T1 seem to imply that more processed particles are observed at $\mathrm{T} 2$ than at $\mathrm{T} 1$. 
Figure 6a shows the scatter plots of OC vs. EC at $\mathrm{T} 1$ and T2. The data points are colored as a function of time during the month-long study. The solid lines are Deming fits. Results by linear least-squares regression and Deming regression analysis are summarized in Table 4. The plots of OC vs. EC contain a large amount of scatter. This indicates that data at both sites could not be analyzed by a simple global linear regression analysis. Nonetheless, the global fit results in the OC:EC value from the fitting slope, which indicated that both primary and secondary organic carbons were observed at $\mathrm{T} 1$ and $\mathrm{T} 2$. When the same data were analyzed on daily basis (LST used to determine start and end points), very little correlation was found between OC and EC (see supplemental materials for details). This further indicates the complexity of the OC and EC observed at both sites. When looking at the same data from a different perspective, e.g. as a function of OC:EC, as shown in Fig. 6b, the trend of the data becomes more obvious. The majority of the data points had OC:EC in the range of 0 to 10 at $\mathrm{T} 1$, while the majority of the data points at T2 had OC:EC in the range of 0 to 20 . The difference in the OC:EC values indicates that the particles at $\mathrm{T} 1$ and $\mathrm{T} 2$ are of different character.

Table 5 shows a comparison of $\mathrm{PM}_{2.5}$ OC and $\mathrm{EC}$ with other metropolitan areas in the world, such as Beijing, Shanghai, Hong Kong, Los Angeles, and Houston. Most of these OC and EC measurements were obtained by thermal optical reflectance methods (Birch, 1998; Cachier et al., 1989; Chow et al., 2001). Since the definitions of OC and EC are operationally defined, uncertainties exist among different methods. The OC:EC values for $\mathrm{T} 1$ and $\mathrm{T} 2$ reported in Table 5 are obtained by Deming regression analysis shown in Fig. 6a. The OC:EC value obtained at T1 is comparable to the average reported for urban US cities (Schichtel et al., 2008). In contrast, the average OC:EC value at $\mathrm{T} 2$ is comparable to places such as Houston (Russell and Allen, 2004) and Milan (Lonati et al., 2007). It is close to the average reported for US rural areas (Schichtel et al., 2008).

Although the averaged $\mathrm{OC}$ and $\mathrm{EC}$ at $\mathrm{T} 1$ and $\mathrm{T} 2$ in the vicinity of Mexico City did not rank the highest in this comparison, one needs to take into account that some of the other measurements were taken in different seasons, i.e. summer, fall, or winter. For example, winter observations usually result in higher mass loadings than those in summer. A better comparison is from Mexico City study in March 1997 (Chow et al., 2002). Six core sites were used in this study, La Merced, Pedregal, Xalostoc, Tlalnepantla, Netzahualcoyotl, and Cerro de la Estrella, mostly representing urban, suburban, residential, industrial, and commercial areas in or near downtown Mexico City. Results reported were averages of all six sites. The $\mathrm{T} 1$ and $\mathrm{T} 2$ comparisons with these results are in reasonable agreement. However, direct comparison with results from the regional sites may be more useful in illustrating changes or trends over the past decade. Unfortunately, the latter were not available. Querol et al. (2008) recently reported the OC and EC results during MILAGRO
(Querol et al., 2008), but only results from T1 were available for comparison. For ease of comparison in the latter case, the $6 \mathrm{~h}$ average of our data is used. The averages of $\mathrm{EC}$ and TC by Querol et al. at T1 are higher than those in this work, where our $6 \mathrm{~h} \mathrm{OC}$ average is higher than that of Querol et al. (2008). More details are provided in the supplemental materials. Since Querol et al. (2008) selected only a few $6 \mathrm{~h}$ samples to determine $\mathrm{OC}$ and $\mathrm{EC}$, their results do not have the same time resolution or as many samples as reported here. We expect, therefore, that our results may provide more complete statistics because of the continuous hourly measurements.

\subsection{The semi-empirical EC tracer method}

Although the OC:EC and EC:TC could be used to get some idea of the extent of primary and secondary organic carbon, quantification of POC and SOC is still quite important to assess the performance of organic aerosol predictions made by models. Identification of POC and SOC is quite important in further analysis. The semi-empirical EC tracer method is used here to derive POC and SOC empirically. The assumptions and methodology of EC tracer method are described in detail elsewhere (Castro et al., 1999; Turpin and Huntzicker, 1991, 1995; Yu et al., 2007). Briefly, total OC ( $\left.\mathrm{OC}_{\text {total }}\right)$ is defined as the sum of POC and SOC, Eq. (1).

$\mathrm{SOC}=\mathrm{OC}_{\text {total }}-\mathrm{POC}$

POC is defined in Eq. (2),

$\mathrm{POC}=\mathrm{EC} \times\left(\frac{\mathrm{OC}}{\mathrm{EC}}\right)_{\mathrm{pri}}$

where $(\mathrm{OC}: \mathrm{EC})_{\text {pri }}$ is the estimated primary carbon ratio. The OC emitted from non-combustion sources, such as emission directly from vegetation, is assumed to be negligible in the approach used here. Using the minimum OC to EC ratio, (OC:EC) $\min$, to substitute for (OC:EC) pri , the SOC and POC can therefore be estimated (Cabada et al., 2004; Castro et al., 1999):

$\mathrm{SOC}=\mathrm{OC}_{\text {total }}-\mathrm{EC} \times\left(\frac{\mathrm{OC}}{\mathrm{EC}}\right)_{\text {min }}$

Several assumptions must be made to deduce SOC and POC in this manner. For instance, samples used to calculate (OC:EC) $\min$ have negligible amounts of SOC. Composition and emission sources of POC and SOC are assumed to be relatively constant spatially and temporally. Contribution from non-combustion POC is assumed low. Contribution from semi-volatile organic compounds is also assumed to be low compared with non-volatile organic species. The determination of (OC:EC) $)_{\min }$ is crucial in this approach.

Several methods are commonly used to derive SOC and POC, including the organic tracer-based receptor model (Schauer et al., 1996, 2002), the reactive chemical transport 

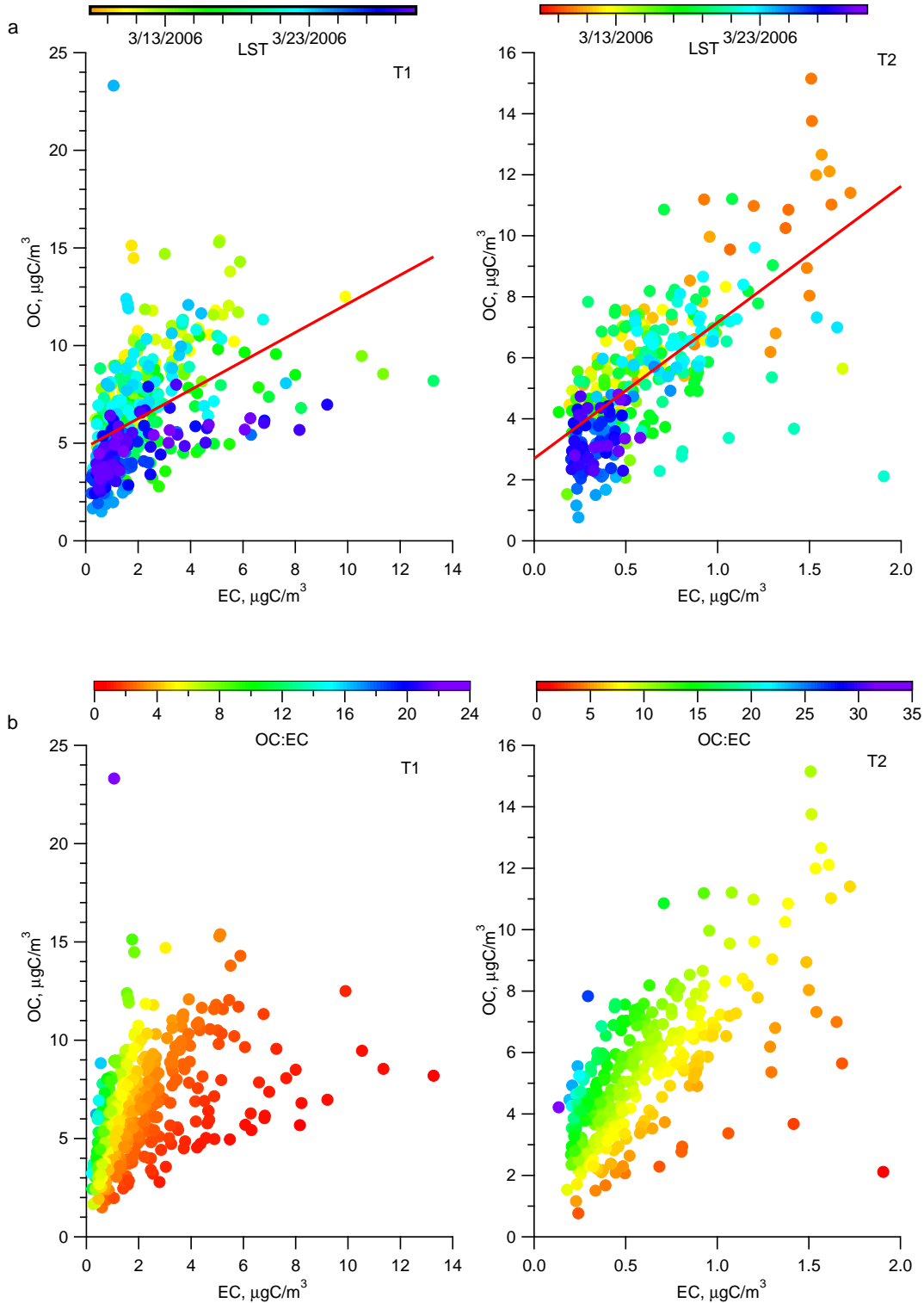

Fig. 6. (a) Scatter plots of OC vs. EC at T1 (left panel) and T2 (right panel), respectively. The solid lines are the global linear least-squares fits using Deming regression analysis. The data points are color coded as a function of date. (b) Scatter plots of OC vs. EC at T1 (left panel) and T2 (right panel), respectively. The data points are color coded as a function of the OC to EC ratio.

model (Pandis et al., 1992; Strader et al., 1999), the nonreactive transport model (Hildemann et al., 1996) and the semi-empirical EC tracer method (Castro et al., 1999; Turpin and Huntzicker, 1995). The EC tracer method is mainly dependent on ambient measurements of OC and EC and therefore is easy to use. The key is to estimate (OC:EC) pri from ambient conditions. The challenge lies because (OC:EC) pri could be influenced by meteorological conditions and emission fluctuations (Turpin and Huntzicker, 1995; Yu, S., et al., 2004).
Previous authors often used the lowest 5\% or $10 \%$ measured OC:EC values in a given season to estimate (OC:EC) $)_{\min }$ (Lim and Turpin, 2002; Yuan et al., 2006). Table 6 summarizes the linear least-squares fit results of OC vs. EC from different subsets of the data from the lowest $2.5 \%, 5 \%$, and $10 \%$ OC:EC values to estimate (OC:EC) pri. For instance, the (OC:EC) pri at $\mathrm{T} 1$ is estimated to be 0.64 using the lowest $5 \%$ of OC:EC values by linear regression analysis. It is worth mentioning that Yuan et al. (2006) found that $(\mathrm{OC}: \mathrm{EC})_{\text {pri }}$ is seasonally-dependent. For instance, the 
Table 3. Statistical summary at $\mathrm{T} 1$ and $\mathrm{T} 2$.

\begin{tabular}{lrrrrr}
\hline $\mathrm{T} 1$ & $\begin{array}{r}\text { Thermal OC } \\
\mu \mathrm{g} \mathrm{C} / \mathrm{m}^{3}\end{array}$ & $\begin{array}{r}\text { Thermal EC } \\
\mu \mathrm{g} \mathrm{C} / \mathrm{m}^{3}\end{array}$ & $\begin{array}{r}\text { Thermal TC } \\
\mu \mathrm{g} \mathrm{C} / \mathrm{m}^{3}\end{array}$ & EC:TC & OC:EC \\
\hline average & 6.4 & 2.1 & 8.5 & 0.23 & 4.5 \\
standard deviation & 3.0 & 1.8 & 4.0 & 0.11 & 2.8 \\
maximum & 29.3 & 13.3 & 29.3 & 0.62 & 21.9 \\
minimum & 1.5 & 0.2 & 1.9 & 0.04 & 0.6 \\
\hline $\mathrm{T} 2$ & & & & & \\
\hline average & 5.4 & 0.6 & 6.0 & 0.10 & 10.1 \\
standard deviation & 2.2 & 0.3 & 2.5 & 0.04 & 1.1 \\
maximum & 15.2 & 1.9 & 16.7 & 0.32 & 26.7 \\
minimum & 0.8 & 0 & 1.0 & 0.04 & 1.1 \\
\hline
\end{tabular}

Table 4. Summary of global linear least-squares fits of Thermal OC vs. Thermal EC at T1 and T2.

\begin{tabular}{lrrr}
\hline \multicolumn{4}{c}{ Thermal OC vs. Thermal EC } \\
Site & Fitting Functions & Linear Least-squares & Deming Least-squares \\
\hline T1 & Slope & $0.74 \pm 0.07$ & $0.93 \pm 0.14$ \\
& Intercept & $4.77 \pm 0.19$ & $4.39 \pm 0.26$ \\
& $R^{2}$ & 0.20 & - \\
\hline $\mathrm{T} 2$ & Slope & $3.79 \pm 0.12$ & $4.30 \pm 0.36$ \\
& Intercept & $3.25 \pm 0.12$ & $3.02 \pm 0.15$ \\
& $R^{2}$ & 0.45 & - \\
\hline
\end{tabular}

$-R^{2}$ is not available as an output of the Deming regression analysis program.

(OC:EC) pri ranged from 0.41 to 0.88 from summer to winter based on observations in Hong Kong (Yuan et al., 2006). Therefore, the (OC:EC) pri determined in this particular study could not be used in all seasons for a similar site in Mexico City.

In addition, a second approach is used to obtain (OC:EC) $)_{\text {pri }}$, since the $R^{2}$ values from the lowest $5 \%$ OC:EC approach are not as satisfactory. Table 7 summarizes the linear least-squares fit results of OC vs. EC grouped by binning OC:EC values in different ranges at each site. The $(\mathrm{OC}: \mathrm{EC})_{\min }=0.61$ at $\mathrm{T} 1$ falls in the range of $\mathrm{OC}: \mathrm{EC}$ values typical of fossil fuel sources. The $R^{2}$ value obtained is 0.95 . On the other hand, (OC:EC) $)_{\min }$ is 2.26 with the $R^{2}=0.86$ at T2. The (OC:EC) min value at T2 falls in the range of OC:EC values typical of biomass emissions (Gelencser et al., 2007). The results from this approach are in reasonable agreement with those using the lowest $2.5 \%$ or $5 \%$ of OC:EC data shown in Table 6. Since the results obtained by binning the OC and EC values to different ranges prior to applying linear least-squares analysis yields improved $R^{2}$ (Tables 6 and 7), the slopes from this regression analysis are used as $(\mathrm{OC}: \mathrm{EC})_{\min }=(\mathrm{OC}: \mathrm{EC})_{\text {pri }}$ to derive SOC and POC at T1 and $\mathrm{T} 2$.
The intercepts from the regression analysis usually are used to estimate non-combustion POC (Cabada et al., 2004). The analysis indicates that non-combustion OC, most likely biomass burning $\mathrm{OC}$, contribute to the overall $\mathrm{OC}$ at $\mathrm{T} 1$ and T2. The uncertainty in estimating SOC and POC usually arises from random measurement errors and the statistical techniques used to derive the primary OC:EC ratios. The relative standard deviations (RSDs) of the OC and EC measurements were independently determined (Bauer et al., 2009). The RSDs of Thermal OC is $5.3 \%$ between the two units deployed in the campaign. Therefore, it is not a major source of measurement uncertainty.

Recently several groups evaluated linear regression techniques, such as linear least-squares, Deming regression, and York regression, which are often used in the EC tracer method to derive secondary and primary organic carbon (Chu, 2005; Saylor et al., 2006). Chu (2005) concluded that Deming fit is better when the biomass burning contribution is high. Similarly, Saylor et al. (2006) found that when limited information is available on the relative uncertainties of OC and EC, then Deming regression is better. The results by using Deming fit are similar to linear regression analysis at both sites. Specifically, the Deming fit slope is $0.63 \pm 0.05$, 
Table 5. Comparison of $\mathrm{PM}_{2.5}$ OC:EC, OC, EC, and TC observed in different cities.

\begin{tabular}{|c|c|c|c|c|c|c|c|c|}
\hline \multirow[t]{2}{*}{ Location } & \multirow[t]{2}{*}{ Duration } & \multirow[t]{2}{*}{ OC:EC } & OC avg & EC avg & $\mathrm{TC}$ & \multirow[t]{2}{*}{ Season } & \multirow[t]{2}{*}{ Method } & \multirow[t]{2}{*}{ Reference } \\
\hline & & & \multicolumn{3}{|c|}{$\mu \mathrm{g} \mathrm{C} / \mathrm{m}^{3}$} & & & \\
\hline Beijing & $\sim 2$ weeks & 2.4 & 9.4 & 4.3 & - & Summer & Rupprecht ambient carbon particulate monitor & (Yu et al., 2006) \\
\hline Beijing & $\sim 3$ months & 3.0 & 20.4 & 6.6 & 26.9 & Fall & Rupprecht ambient carbon particulate monitor & (Duan et al., 2005) \\
\hline Shanghai & 1 week & - & 7.9 & 3.5 & 11.4 & Summer & Sunset OCEC analyzer NIOSH protocol & (Feng et al., 2006) \\
\hline Guangzhou & 1 week & - & 14.5 & 6.3 & 20.8 & Summer & Sunset OCEC analyzer NIOSH protocol & (Feng et al., 2006) \\
\hline Hong Kong & $\sim 4$ months & $2-3$ & 12 & 6 & - & Winter & Thermal manganese dioxide oxidation & (Ho et al., 2002) \\
\hline Hong Kong & $\sim 2$ months & 2.4 & 14.7 & 6.1 & - & Winter & IMPROVE thermal optical reflectance method & (Cao et al., 2003) \\
\hline Houston & $\sim 2$ years & $2.9-4.8$ & $2.4-4.3$ & $0.3-0.6$ & - & All & NIOSH thermal optical reflectance method & (Russell and Allen, 2004) \\
\hline Los Angeles & $\sim 4$ months & 2.5 & 8.3 & 2.4 & $2-$ & Summer & IMPROVE thermal optical reflectance method & (Chow et al., 1994) \\
\hline Milan & $\sim 5$ month & 4.2 & 5.2 & 1.2 & - & Summer & NIOSH thermal optical reflectance method & (Lonati et al., 2007) \\
\hline Madrid & $\sim 1$ month & 2.7 & 4 & 1 & - & Summer & EPA thermo-optical transmittance technique & (Plaza et al., 2006) \\
\hline Barcelona & $\sim 5$ weeks & 2.8 & 3.9 & 1.9 & 5.8 & Summer & Sunset OCEC analyzer NIOSH protocol & (Viana et al., 2007) \\
\hline Amsterdam & $\sim 5$ weeks & 2.6 & 3.6 & 1.5 & 5.1 & Summer & Sunset OCEC analyzer NIOSH protocol & (Viana et al., 2007) \\
\hline US rural & $\sim 2$ years & $2.3-4.0 *$ & - & - & - & Summer & IMPROVE thermal optical reflectance method & (Schichtel et al., 2008) \\
\hline US urban & $\sim 2$ years & $1.1-1.7 *$ & - & - & - & Summer & IMPROVE thermal optical reflectance method & (Schichtel et al., 2008) \\
\hline Mexico & $\sim 3$ weeks & $1.7 * *$ & 9.9 & 5.8 & 15.8 & Spring & IMPROVE thermal optical reflectance method & (Chow et al., 2002) \\
\hline Mexico - T1 & $\sim 4$ weeks & - & 3.7 & 4.0 & 16 & Spring & IMPROVE thermal optical reflectance method & (Querol et al., 2008) \\
\hline Mexico - T1 & $\sim 2$ weeks & - & 5.0 & 1.6 & - & Spring & Sunset OCEC analyzer modified NIOSH protocol & (Stone et al., 2008) \\
\hline Mexico - T1 & $\sim 4$ weeks & - & 6.1 & 1.5 & 8.2 & Spring & Sunset OCEC analyzer modified NIOSH protocol & (Hennigan et al., 2008) \\
\hline Mexico - T1 & $\sim 4$ weeks & 0.9 & 6.4 & 2.1 & 8.5 & Spring & Sunset OCEC analyzer modified NIOSH protocol & This work \\
\hline Mexico - T2 & $\sim 4$ weeks & 10.1 & 5.4 & 0.6 & 6.0 & Spring & Sunset OCEC analyzer modified NIOSH protocol & This work \\
\hline
\end{tabular}

* Derived from EC/TC 82nd-98th percentile ratios.

** Derived from OC/TC.

- Not available from original references.

Table 6. Summary of linear least-squares analysis fitting results grouped by the lowest percentage of OC:EC ratios at T1 and T2.

\begin{tabular}{llllll}
\hline Site & Lowest \% by OC:EC & No. of data & Slope & Intercept & $R^{2}$ \\
\hline $\mathrm{T} 1$ & $2.5 \%$ & 12 & $0.49 \pm 0.09$ & $2.66 \pm 0.77$ & 0.75 \\
& $5 \%$ & 25 & $0.64 \pm 0.10$ & $2.07 \pm 0.71$ & 0.65 \\
& $10 \%$ & 50 & $0.64 \pm 0.08$ & $2.69 \pm 0.46$ & 0.58 \\
\hline $\mathrm{T} 2$ & $2.5 \%$ & 12 & $2.82 \pm 0.53$ & $0.54 \pm 0.61$ & 0.74 \\
& $5 \%$ & 24 & $3.43 \pm 0.46$ & $0.64 \pm 0.48$ & 0.71 \\
& $10 \%$ & 48 & $3.71 \pm 0.41$ & $1.14 \pm 0.37$ & 0.62 \\
\hline
\end{tabular}

Table 7. Summary of linear least-squares analysis fitting results to determine the minimum $\mathrm{OC}: \mathrm{EC}$ ratios at $\mathrm{T} 1$ and $\mathrm{T} 2$.

\begin{tabular}{lllll}
\hline Site & No. of data & Slope & Intercept & $R^{2}$ \\
\hline T1 & 36 & $0.61 \pm 0.02$ & $1.63 \pm 0.12$ & 0.95 \\
T2 & 12 & $2.26 \pm 0.28$ & $0.76 \pm 0.28$ & 0.86 \\
\hline
\end{tabular}

and the intercept $1.52 \pm 0.13$ at $\mathrm{T} 1$, respectively. The Deming fit slope is $2.39 \pm 0.62$, and the intercept $0.66 \pm 0.35$ at $\mathrm{T} 2$, respectively. Since the results by linear least-squares regression and Deming regression are very comparable, results by the linear least-squares analysis are used.

\subsection{SOC and POC at T1 and T2}

Figures $7 \mathrm{a}$ and $\mathrm{b}$ show the time series of OC, EC, SOC, POC, SOC\%, wind direction, and wind speed at $\mathrm{T} 1$ and $\mathrm{T} 2$, respectively. The $\mathrm{SOC}_{\mathrm{OC}} \%$ is defined as $\mathrm{SOC}_{\mathrm{OC}} \%=\mathrm{SOC} / \mathrm{OC} \times 100 \%$, and $\mathrm{SOC}_{\mathrm{TC}} \%$ is defined as $\mathrm{SOC}_{\mathrm{TC}} \%=\mathrm{SOC} / \mathrm{TC} \times 100 \%$. In addition, the entire sampling period was categorized into three types of conditions: "transport likely" (shaded in gray), "unlikely" (shaded in blue), and "possible" (shaded in green), based on local observed wind profiles (Fast et al., 2007). During "transport likely" days (9 March-12 March, 18 March-22 March, 24 March25 March, and 30 March 2006), the wind direction is southwesterly or westerly. The wind direction during transport possible days is southerly or westerly (8 March, 17 March, 


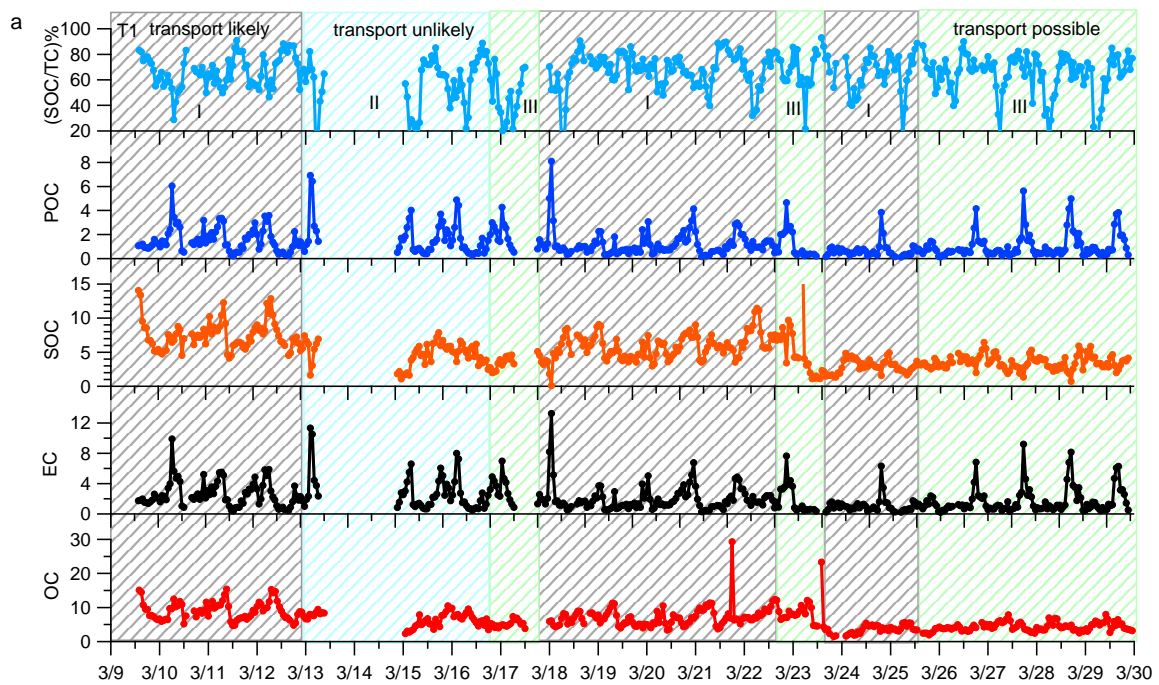

LST

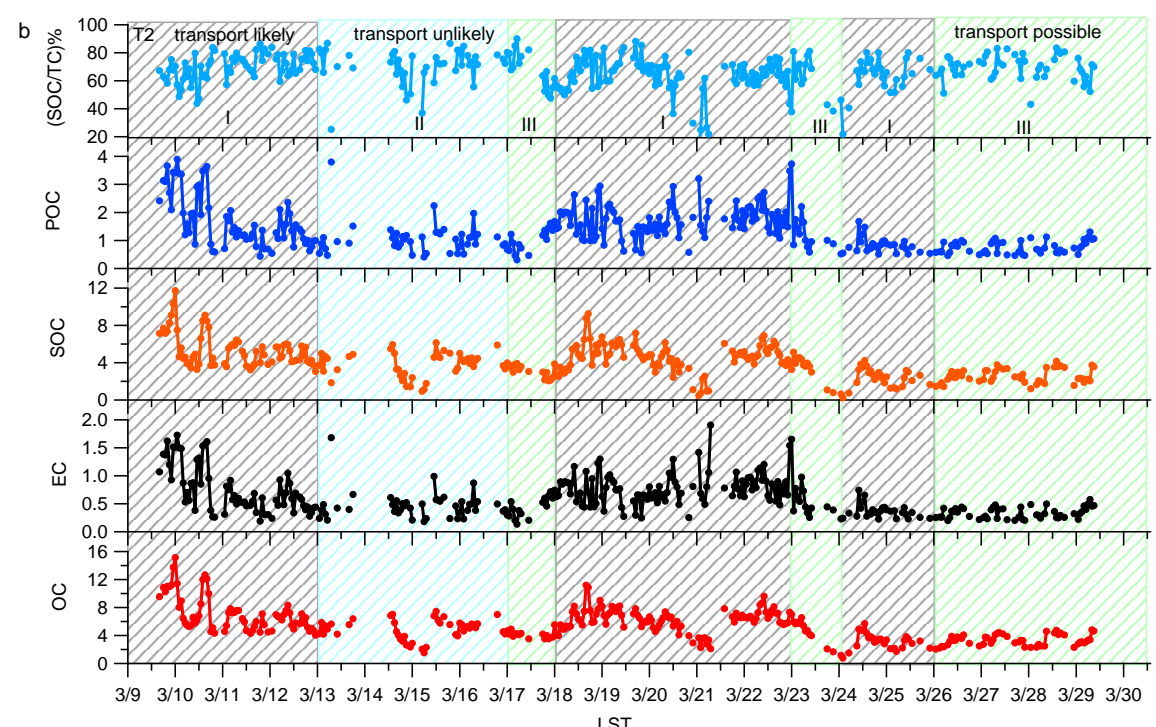

Fig. 7. (a) Time series of OC, EC, POC, SOC, SOC\%, wind direction, and wind speed at T1. (b) Time series of OC, EC, POC, SOC, SOC\%, wind direction, and wind speed at $\mathrm{T} 2$.

23 March, and 26 March-29 March 2006). The wind direction during "transport unlikely" days is predominantly northerly (13 March-16 March 2006). It is difficult to see the effect of meteorology from Figs. 7a and b; however, other analysis will be used later to investigate this effect.

The $\mathrm{SOC}_{\mathrm{OC}} \%(\mathrm{SOC} / \mathrm{OC} \times 100 \%)$ at $\mathrm{T} 1$ ranged from 1.2 to $97.2 \%$ with an average of $80.2 \pm 14.3 \%$. The $\mathrm{SOC}_{\mathrm{OC}} \%$ at $\mathrm{T} 2$ ranged from $12.8-98.6 \%$ with an average of $74.4 \pm 11.3 \%$. The $\mathrm{SOC}_{\mathrm{TC}} \%(\mathrm{SOC} / \mathrm{TC} \times 100 \%)$ at $\mathrm{T} 1$ ranged from $0.5-$ $93.8 \%$ with an average of $63.5 \pm 17.2 \%$. The $\mathrm{SOC}_{\mathrm{TC}} \%$ at $\mathrm{T} 2$ ranged from 9.3 to $98.1 \%$ with an average of $67.4 \pm 12.4 \%$. The propagated errors of $\mathrm{SOC}_{\mathrm{OC}} \%$ and $\mathrm{SOC}_{\mathrm{TC}} \%$ are estimated to be $15.9 \%$ and $15.8 \%$, respectively, when using the RSDs determined for OC, TC, and assuming that SOC bearing the same degree of uncertainty from measurement and additional error from the EC-tracer method, i.e. 5.3\% for OC, $4.9 \%$ for TC, and $15 \%$ for SOC. The SOC\% values observed in Mexico City suburban and rural areas are close to what is observed in other locations with high secondary organic carbon, such as up to $80 \%$ in Southern California (Turpin and Huntzicker, 1995), 63-76\% in Europe (Gelencser et al., 2007), 50-95\% in Beijing (Dan et al., 2004), 84\% in Milan (Lonati et al., 2007), and $78 \%$ on the Portuguese coast (Castro et al., 1999). 

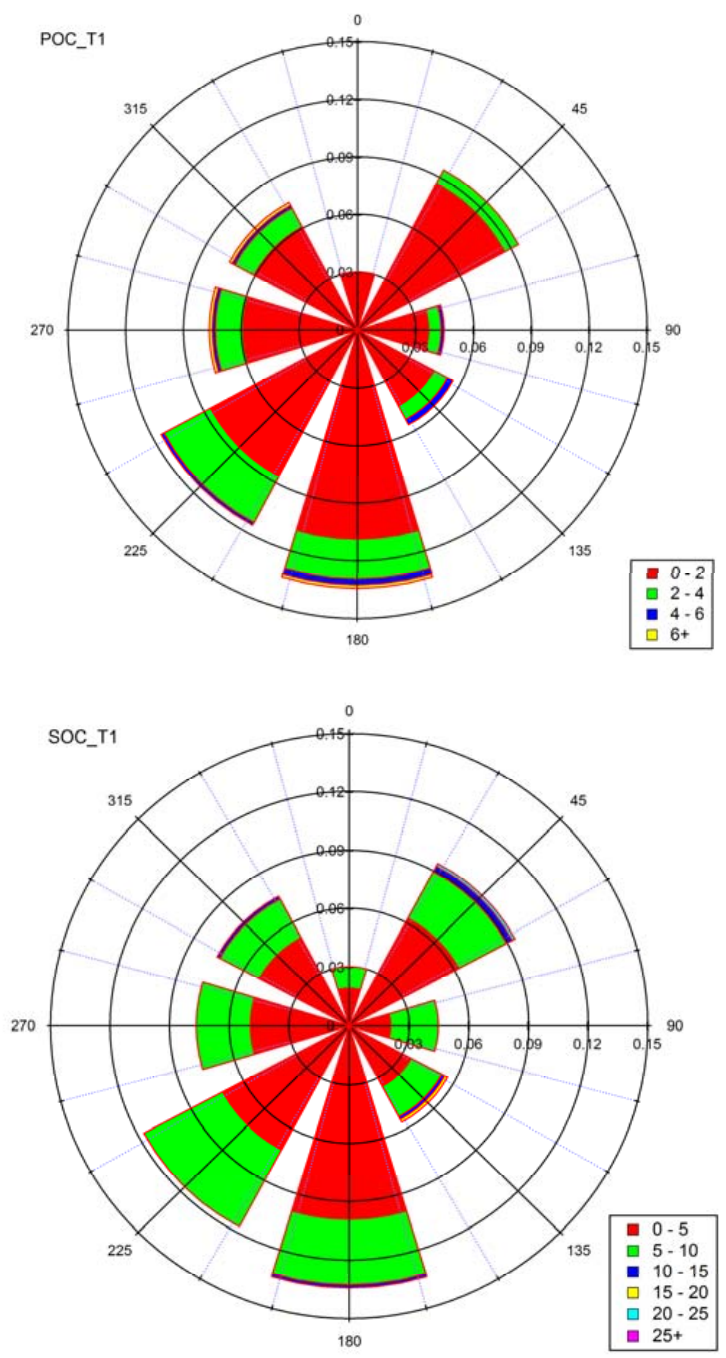

Fig. 8. Wind roses of POC and SOC at T1 (left) and T2 (right).

The OC and EC observed at T1 and T2 were strongly influenced by the meteorological conditions as shown in Fig. 8 . Predominant wind directions at T1 were southerly, southwesterly, and north-easterly. Predominant wind directions at T2 were southerly and north-westerly. The favorable transport conditions downwind of Mexico City mostly were from the south-west (Fast et al., 2007). Since only hourly data were used in this analysis, they may not reflect the dynamics of rapid wind changes at the surface. However, this analysis does seem to provide a good idea of the effect of meteorological conditions on particulate matter mass loadings.

Emissions originated from Mexico City were anticipated and observed at T1. However, emissions from other directions, e.g. from the northwest and northeast, were higher than anticipated. The Tula-Vita-Apasco industrial corridor is $60 \mathrm{~km}$ north-north-west from the center of Mexico City. For instance, there is a large refinery and a power plant in Tula. Emissions from industrial sources from the north and
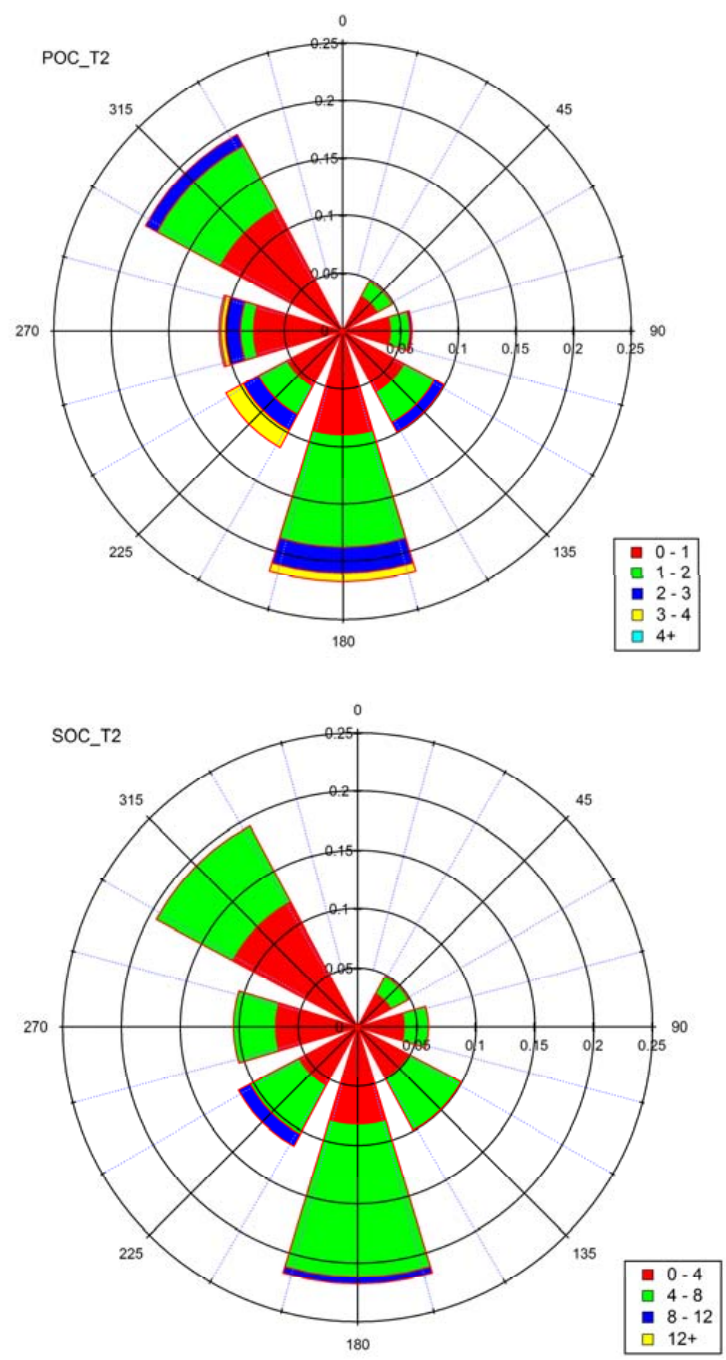

northwest, such as just mentioned, may have contributed to the POC and SOC observed at T1. Emissions from the southeast may come from the active volcano, Popocatepetl, $70 \mathrm{~km}$ southeast of the Mexico City, and Puebla, $129 \mathrm{~km}$ southeast of the Mexico City. Emissions from the northeast may come from urban corridor along a highway. Similarly, emissions from sources other than Mexico City were likely transported over at T2. A striking feature of the POC and SOC observed at $\mathrm{T} 2$ was the strong influence from northwest. Contributions of emissions from the Tula-Vita-Apasco industrial areas may have had a stronger impact at $\mathrm{T} 2$ than $\mathrm{T} 1$.

Doran et al. (2008) recently used a Lagrangian dispersion model driven by the Weather Research and Forecasting (WRF) mesoscale model with four-dimensional data assimilation to simulate the dispersion of elemental carbon over a region encompassing Mexico City and its surroundings. Their results present a good example of simulating local, regional, and synoptic meteorological conditions during the 
MILAGRO study. Detailed study of emissions, usage of emission inventories, and the influence of emissions on observations were presented in this previous study, and not repeated here.

Figure 9 depicts scatter plots of SOC vs. TC and POC vs. TC during the three T1 to T2 transport scenarios - likely, possible and unlikely. The solid lines are linear least-squares fits. During T1 to T2 favorable transport dates, i.e. likely and possible dates, the slopes generated by SOC vs. TC regression analysis were very similar between $\mathrm{T} 1$ and $\mathrm{T} 2$. However, this was not true with the T1 to T2 unlikely transport days. Similarly, the slopes generated by POC vs. TC regression analysis were almost identical during $\mathrm{T} 1$ to $\mathrm{T} 2$ likely and possible transport days, whereas the same was not true for unlikely transport days. This analysis indicates that we observed different patterns in the SOC and POC due to transport between $\mathrm{T} 1$ and $\mathrm{T} 2$ driven by meteorological conditions.

\subsection{Comparison of SOA and POA at T1}

Results from newer measurement techniques, such as the Aerodyne Aerosol Mass Spectrometer (AMS) (Canagaratna et al., 2007) and the Particle-Into-Liquid Sampler coupled with Total Organic Carbon analyzer (PILS-TOC), were analyzed to derive secondary organic aerosols (Sullivan et al., 2006). The approach used by Takegawa et al. (2006), to analyze the AMS data is conceptually similar to the semiempirical EC tracer method; whereas secondary organic aerosol (SOA) formation was inferred from direct measurements of water-soluble organic carbon (WSOC) by PILSTOC. Since the PILS data were not available for comparison, only the comparison between data from the AMS and the Sunset OCEC analyzer is presented.

A two component positive matrix factorization analysis (PMF) of the AMS data results in deconvoluted OOA (oxygenated organic aerosol), HOA (hydrocarbon-like organic aerosol (Lanz et al., 2007; Ulbrich et al., 2009). Comparisons with other gas and aerosol phase measurements at $\mathrm{T} 1$ indicate that the HOA component reflects primary organic aerosols generated by combustion processes (i.e. vehicle emissions and some trash/biomass burning); while the OOA component reflects secondary organic aerosol species (de Gouw et al., 2009). In order to make a meaningful comparison between the POC, SOC, and OC determined by the Sunset OCEC field analyzer and the AMS component mass concentrations, we calculate POA and SOA concentrations taking into account of the estimated OM/OC ratios of the two components. Aiken et al. used the High Resolution ToF AMS measurements to obtain $\mathrm{OM} / \mathrm{OC}$ ratios of $1.38,1.95$, and 1.55 for the HOA, OOA, and BBOA (biomass burning organic aerosol) components measured at the T0 site during the MILAGRO study (Aiken et al., 2008). Since the HOA component at $\mathrm{T} 1$ is influenced by vehicle emissions as well as biomass burning, we estimate its $\mathrm{OM} / \mathrm{OC}$ ratio to be 1.4 , the average of the $\mathrm{HOA}$ and $\mathrm{BBOA}$ values determined at $\mathrm{T} 0$; the $\mathrm{OM} / \mathrm{OC}$ ratio for the T1 OOA component is estimated to be identical to the T0 value of 1.95 . Figure 10 depicts the comparison of AMS HOA, OOA, and OM vs. Sunset determined POA $(\mathrm{POC} \times 1.4)$, SOA $(\mathrm{SOC} \times 1.95)$, and $\mathrm{OM}$ $(\mathrm{OM}=\mathrm{POA}+\mathrm{SOA})$, respectively. The Sunset POA, SOA, OM are in red, and the quantities determined by AMS in blue for HOA, OOA, and OM, respectively. Scatter plots of corresponding quantities by AMS and Sunset are also presented.

The Deming linear least-squares fit results in a slope of $0.8 \pm 0.1$ for AMS OM vs. Sunset OM, $1.2 \pm 0.2$ for AMS HOA vs. Sunset POA, $0.5 \pm 0.2$ for AMS OOA vs. Sunset $\mathrm{SOA}(\mathrm{SOA}=\mathrm{SOC} \times 1.4)$, and $0.4 \pm 0.1$ for AMS OOA vs. Sunset $\mathrm{SOA}(\mathrm{SOA}=\mathrm{SOC} \times 1.95)$.

As to the OM comparison, several factors could contribute to these results. The first is the conversion factor used to convert OC to OM by the Sunset measurements. The Deming linear regression analysis of AMS total OM vs. Sunset OC results in a slope of $1.2 \pm 0.2$. If 1.2 were used to convert the Sunset OC to OM, the difference of the total OM determined by the AMS and those by Sunset instruments is reduced. However, recent studies by the high resolution AMS indicate that the conversion factors for POA and SOA may not be the same (Aiken et al., 2008). Therefore, we use the sum of POA and SOA to arrive at OM. Second the size cut of AMS and the Sunset OCEC differs. The former is approximately $1 \mu \mathrm{m}$ and the latter $2.5 \mu \mathrm{m}$, which could contribute to the difference in total organic matter mass loadings.

As to POA, a comparison was made between the AMS HOA vs. POA (Sunset). The general trend between the HOA and POA is in agreement over the entire field study period. As to SOA, two sets of comparison were made: AMS OOA vs. $\mathrm{SOA}(\mathrm{SOA}=\mathrm{SOC} \times 1.95)$ and AMS OOA vs. SOA $(\mathrm{SOA}=\mathrm{SOC} \times 1.4)$. One factor contributing to the difference is the conversion factor used to convert SOC to SOA. The factor determined by Aiken et al. (2008), i.e. 1.95, results in higher SOA compared with the factor 1.4 determined by an earlier review (Turpin et al., 2000). Similarly, another factor contributing to the difference is size cut as discussed in the OM comparison. Since the OC emitted from noncombustion sources (vegetation etc.), as well as emissions directly from biomass burning, are assumed to be negligible in the EC-tracer method, it can not be used to derive BBOA. In future studies we plan to investigate the differences among different methods used to arrive at SOA and POA in more detail.

\subsection{Weekday and weekend patterns}

Diurnal variations of carbon concentrations at $\mathrm{T} 1$ and $\mathrm{T} 2$ during weekdays and weekends over the duration of the campaign are shown in Fig. 11. As discussed earlier, diurnal patterns of OC and EC were observed at $\mathrm{T} 1$ and $\mathrm{T} 2$. This could be a result of not only boundary layer dilution, but also traffic emissions during weekdays and weekends. General features of daily maxima of OC, EC, and TC are shown in Fig. 3. We 

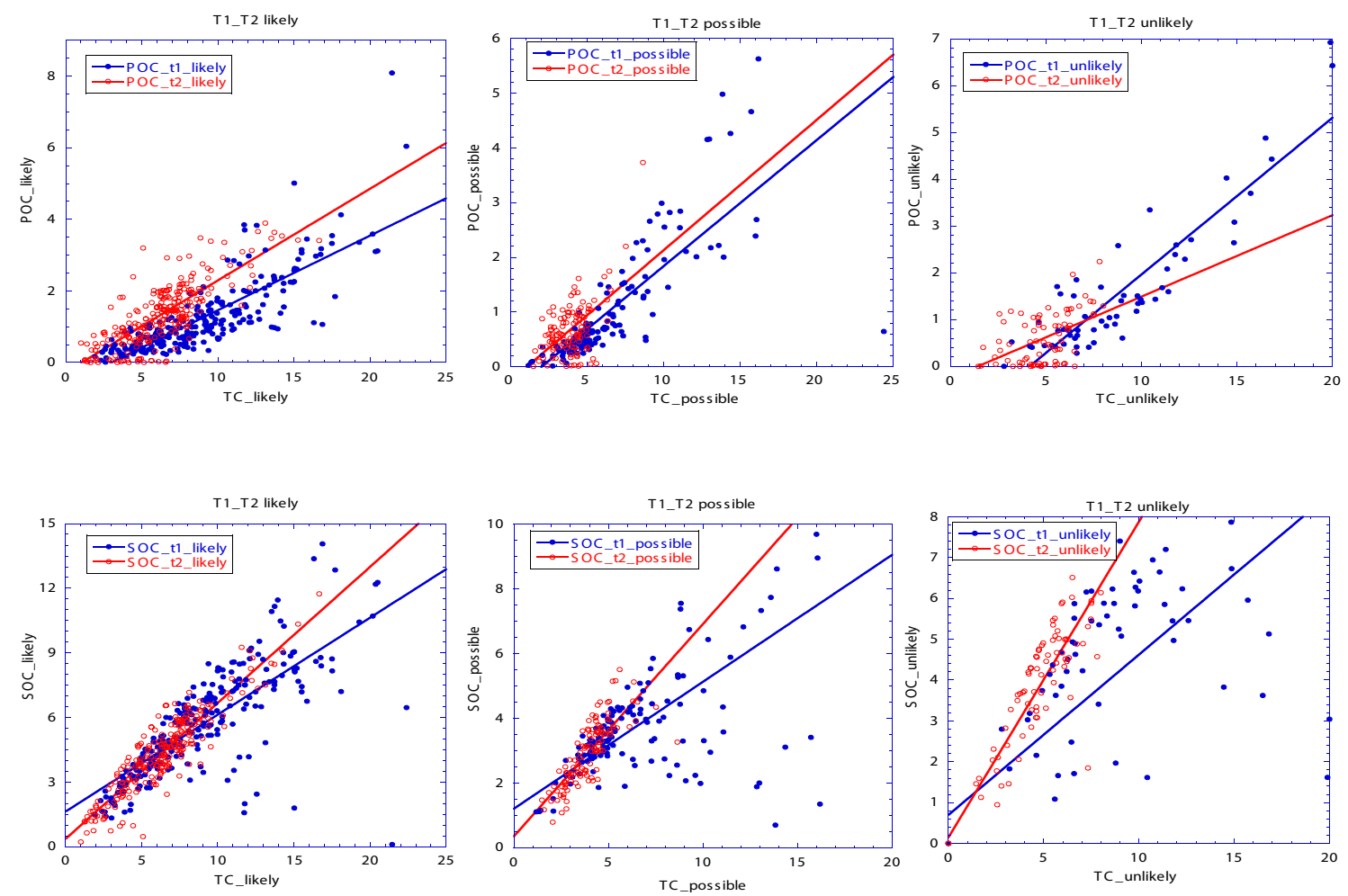

Fig. 9. Scatter plots of SOC vs. TC and POC vs. TC during the three transport scenarios between T1 to T2, transport likely, possible, and unlikely dates. The solid lines are linear least-squares fits.

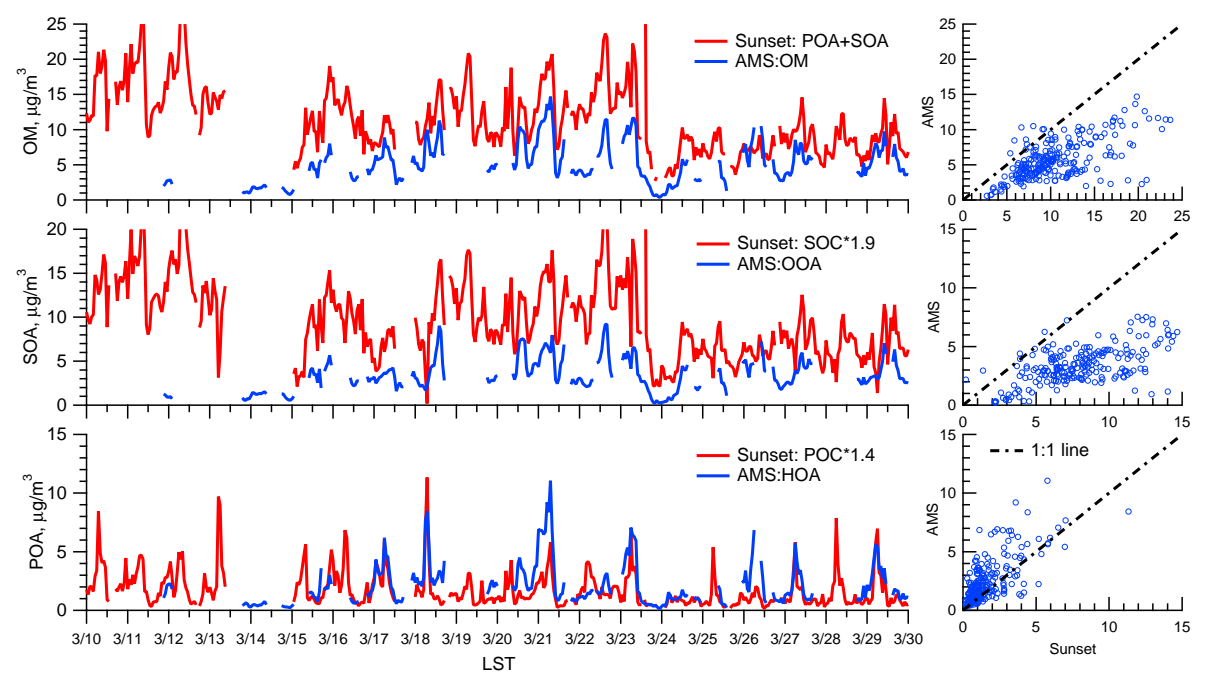

Fig. 10. Comparison of the AMS HOA, OOA, and OM vs. the Sunset POA, SOA, and OM at T1.

now focus on the difference between weekday and weekend patterns. The OC:EC and SOC:POC values are in a similar range during the weekdays and the weekend at $\mathrm{T} 1$. On the other hand, OC:EC values at $\mathrm{T} 2$ are slightly higher during the weekdays than the weekends.
There are some major differences in the OC, EC, SOC and POC patterns between weekdays and weekends at T1 (Fig. 11a). The EC has two pronounced peaks between 05:00-10:00 a.m. (LST) and 08:00 p.m.-02:0 a.m. during the weekend, whereas the EC has one major peak between 05:00-10:00 a.m., and a weaker peak at night time during 

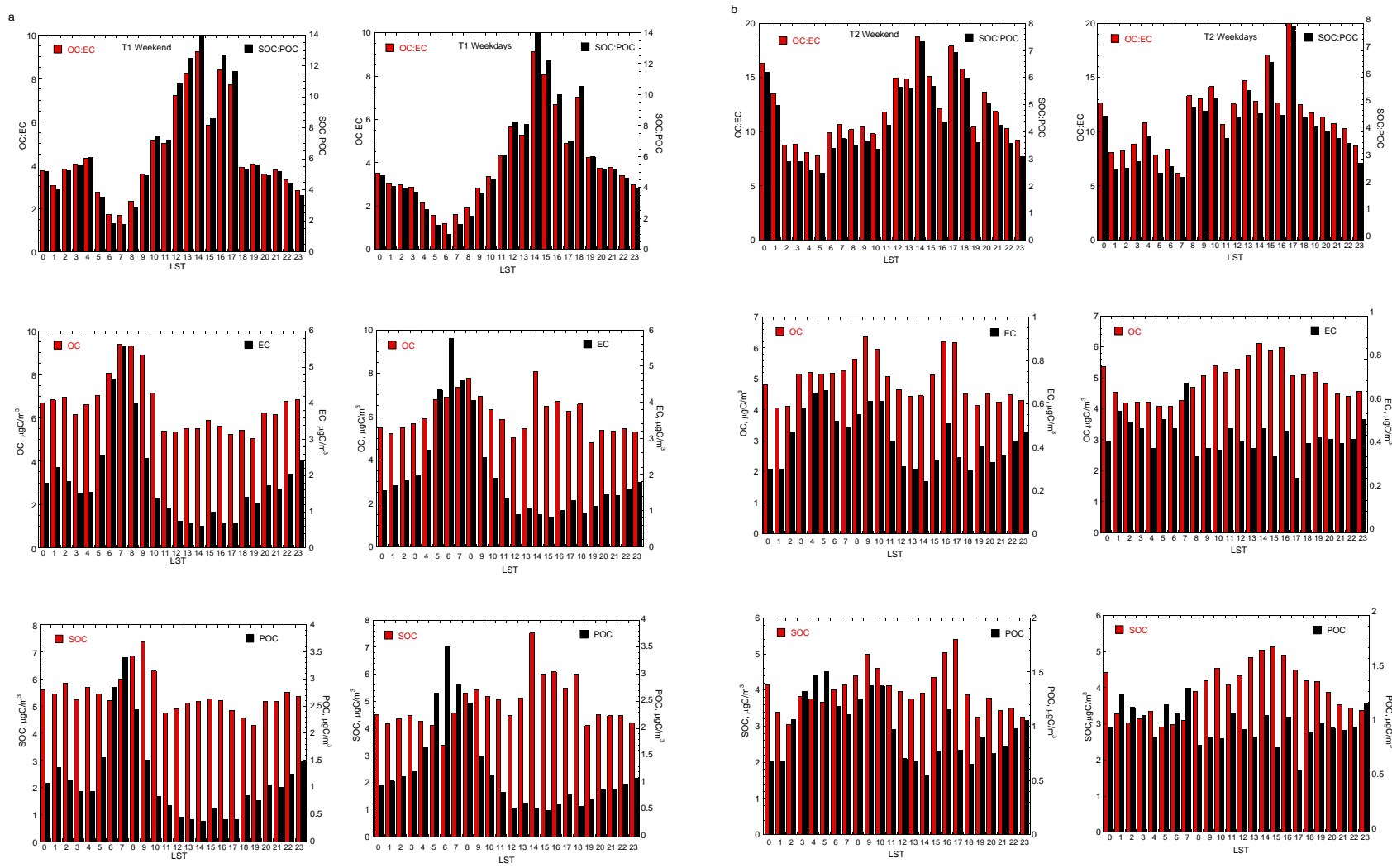

Fig. 11. (a) Average weekend (left column) and weekday (right column) patterns of EC, OC, POC, SOC, OC/EC, and SOC/POC, at T1. (b) Average weekend (left column) and weekday (right column) patterns of EC, OC, POC, SOC, OC/EC, and SOC/POC, at T2.

weekdays. This bimodal behavior of EC could be caused by increasing vehicle emissions in the latter part of the day in the weekends. The OC has two peaks during the weekdays at T1. The first occurs between 05:00 to 10:00 a.m., and the second between noon to 06:00 p.m. The OC shares some similar features over the weekend. However, the magnitude of OC mass loadings is slightly higher between 05:00 to 10:00 a.m. on the weekend compared weekdays. The magnitude of OC mass loadings is slightly lower in the afternoon rush hours during the weekend compared with weekdays. In addition, a third OC peak occurs in the evening starting at 08:00 p.m. and ending at 02:00 a.m. in the morning during the weekend. In contrast, the OC mass loadings remain fairly constant at the same time in the weekdays. These observed features indicate that different traffic patterns could have an influence on the OC and EC mass loadings between weekdays and weekends.

The OC:EC and SOC:POC values are in a similar range during weekdays and the weekend at T2 (Fig. 11b). The major difference of the OC and EC patterns between weekdays and weekends at $\mathrm{T} 2$ is that the OC and EC peaks are slightly delayed after sunrise during the weekend. For instance, the first EC peak after sunrise occurs at 07:00 a.m. during weekdays, whereas it occurs at 08:00-10:00 a.m. during the weekends. Similarly, the OC maximum occurs between noon and $4 \mathrm{pm}$ during the weekdays, whereas it delays to 02:0006:00 p.m. during the weekend. Peaks of OC and EC were often observed during morning and late afternoon rush hours (Allen et al., 1999; Chow et al., 2006; Jeong et al., 2004; Lim and Turpin, 2002; Plaza et al., 2006; Salma et al., 2004). Diurnal variations of SOC have been observed elsewhere (Harley et al., 2005; Strader et al., 1999). SOC formation could increase OC:EC values, while other sources could also complicate the determination of the stable primary emission ratio (Harley et al., 2005). It is known that the afternoon OC increase could be attributed to a combination of photochemical conversion of urban pollutants and boundary layer convection followed by vertical and horizontal transport to non-urban locations. These observations indicate that differences in traffic patterns between weekdays and weekends at the suburban and rural sites may have affected the daily variations of carbon in addition to meteorological conditions (Watson and Chow, 2002).

A chemical mass balance model (CMB) based on molecular marker species was used to determine the relative contribution of major sources to ambient OC at T0 and T1 (Stone et 

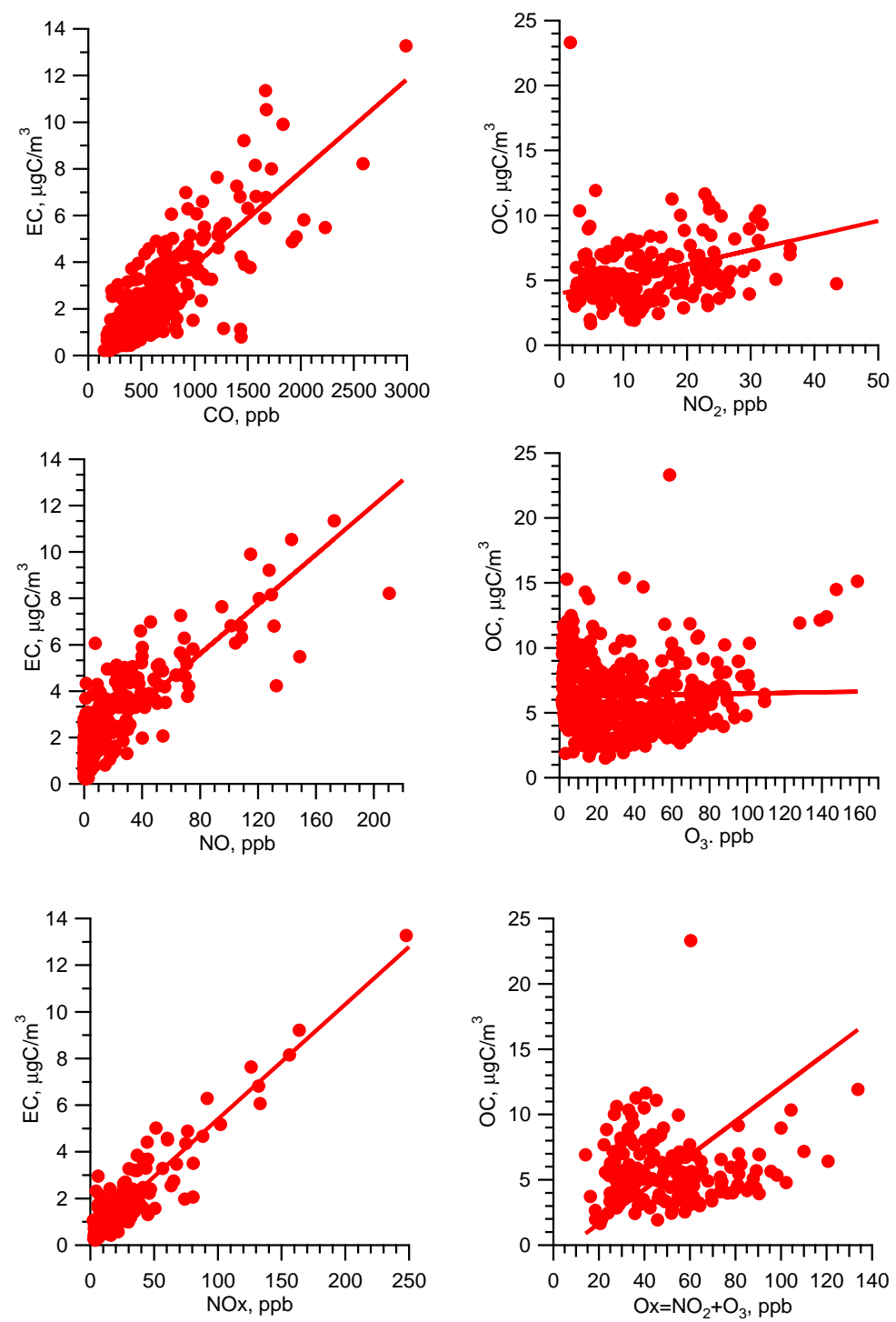

Fig. 12. Scatter plots of EC vs. $\mathrm{CO}, \mathrm{EC}$ vs. $\mathrm{NO}, \mathrm{EC}$ vs. $\mathrm{NO}_{\mathrm{x}}\left(\mathrm{NO}_{\mathrm{x}}=\mathrm{NO}+\mathrm{NO}_{2}\right)$ and $\mathrm{OC}$ vs. $\mathrm{NO}_{2}, \mathrm{OC}_{\mathrm{fs}} \mathrm{O}_{3}$, and $\mathrm{OC}$ vs. $\mathrm{O}_{\mathrm{x}}\left(\mathrm{O}_{\mathrm{x}}=\mathrm{NO}_{2}+\mathrm{O}_{3}\right)$ at $\mathrm{T} 1$. The solid lines are linear least-squares fits.

al., 2008). CMB uses a set of molecular markers to apportion source contributions to ambient PM (Schauer et al., 1996). Model outputs usually include relative contribution of vegetative detritus, diesel engines, gasoline vehicles, smoking vehicles, representative wood smoke, and non-apportioned or other sources of ambient OC. Motor vehicles were found to contribute $32 \%$ of ambient OC at T1 by Stone et al. (2008). $\mathrm{T} 1$ was also found to be influenced by local aerosol sources than urban outflow. Our observations and conclusions are in good agreement with these findings at $\mathrm{T} 1$.

\subsection{EC, OC, POC, and SOC vs. trace gases}

The average $\mathrm{EC}$ to $\mathrm{PM}_{2.5}$ percentage $\left(\mathrm{EC}_{\mathrm{PM}} \%=\right.$ $\left.\mathrm{EC} / \mathrm{PM}_{2.5} \times 100 \%\right)$ and $\mathrm{OC}_{\mathrm{PM}} \%$ were $6.0 \%$ and $20.0 \%$ over the entire sampling time at $\mathrm{T} 1$. The average POC to PM percentage $\left(\mathrm{POC}_{\mathrm{PM}} \%\right)$ and $\mathrm{SOC}_{\mathrm{PM}} \%$ were $3.7 \%$ and $16.3 \%$, respectively. The maximum $\mathrm{EC}_{\mathrm{PM}} \%$ was $21.2 \%$ and the maximum $\mathrm{OC}_{\mathrm{PM}} \%$ was $57.2 \%$. The maximum $\mathrm{POC}_{\mathrm{PM}} \%$ was $12.9 \%$ and the maximum $\mathrm{SOC}_{\mathrm{PM}} \%$ was $49.7 \%$. These findings are similar to observations in metropolitan areas such as Beijing, Hong Kong, or Los Angeles (Duan et al., 2005; Turpin et al., 1991; Yu, J. Z., et al., 2004).

Since trace gases such as $\mathrm{CO}, \mathrm{NO}, \mathrm{NO}_{2}, \mathrm{NO}_{\mathrm{x}}, \mathrm{O}_{3}$, and $\mathrm{SO}_{2}$ play an important role in particulate formation and transformation, examining the relationship between $\mathrm{EC}, \mathrm{OC}$ (POC and SOC) vs. trace gas species could provide more information on emissions sources (Chen et al., 2001). Scatter plots of $\mathrm{EC}$ vs. $\mathrm{CO}, \mathrm{EC}$ vs. $\mathrm{NO}$, and $\mathrm{EC}$ vs. $\mathrm{NO}_{\mathrm{x}}$ $\left(\mathrm{NO}_{\mathrm{x}}=\mathrm{NO}+\mathrm{NO}_{2}\right)$ of observations at $\mathrm{T} 1$ show reasonable 

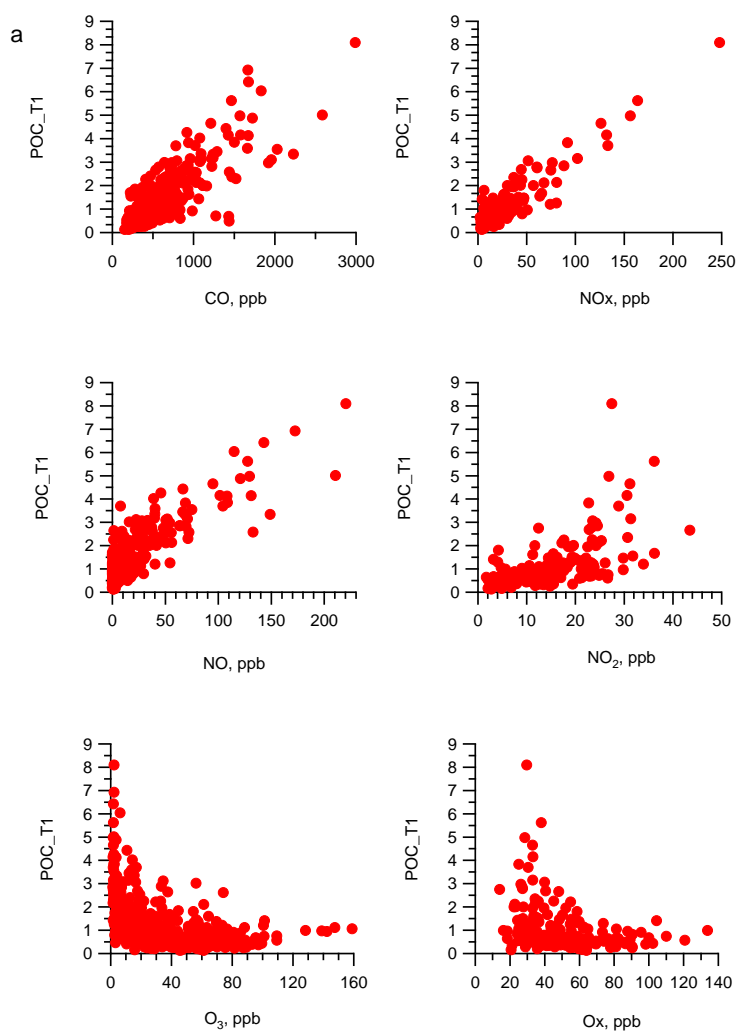
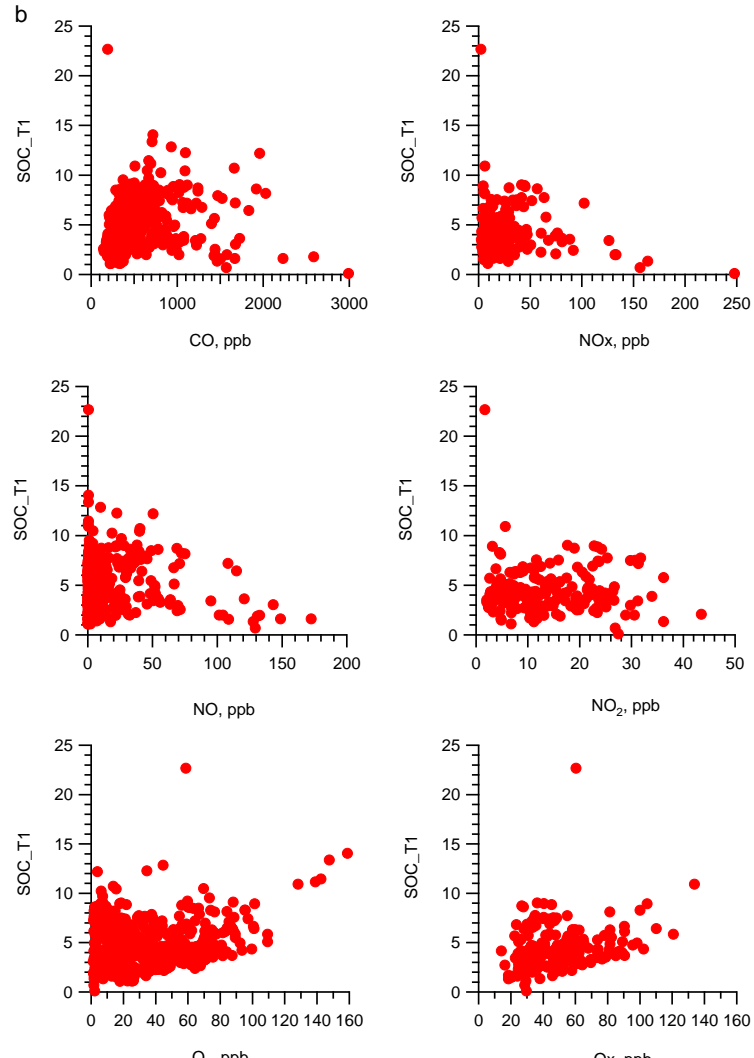

Ox, ppb

Fig. 13. (a) Scatter plots of POC vs. CO, POC vs. $\mathrm{NO}_{\mathrm{x}}, \mathrm{POC}$ vs. $\mathrm{NO}, \mathrm{POC}$ vs. $\mathrm{NO}_{2}, \mathrm{POC}$ vs. $\mathrm{O}_{3}$, and POC vs. $\mathrm{O}_{\mathrm{x}}$ respectively at $\mathrm{T} 1$. (b) Scatter plots of SOC vs. CO, SOC vs. $\mathrm{NO}_{\mathrm{x}}$, SOC vs. NO, SOC vs. $\mathrm{NO}_{2}, \mathrm{SOC}$ vs. $\mathrm{O}_{3}$, and SOC vs. $\mathrm{O}_{\mathrm{x}}$ respectively at T1.

correlations (Fig. 12), which indicate that EC had nearby sources, such as traffic emissions, at the T1 site. Scatter plots of $\mathrm{EC}$ vs. $\mathrm{SO}_{2}$ and $\mathrm{EC}$ vs. $\mathrm{O}_{3}$ did not provide any strong correlations. Since $\mathrm{SO}_{2}$ and $\mathrm{O}_{3}$ were likely involved in secondary particle formation, this result is not surprising. Please refer to supplemental materials for all figures mentioned for $\mathrm{EC}$ and $\mathrm{OC}$ vs. trace gas species.

Since NO is a primary pollutant emitted from combustion processes, its correlation with EC confirms the primary nature of EC. Carbon monoxide is produced via incomplete combustion processes, mainly via motor vehicles exhaust in urban areas. It is often highly correlated with EC emissions (Baumgardner et al., 2002; Chen et al., 2001; Park et al., 2005a; Wang et al., 2004). The EC to CO ratio (EC/CO) derived by linear regression analysis can be used to differentiate sources of air masses and estimate $\mathrm{EC}$ or $\mathrm{CO}$ emissions when direct measurements are not available. The $\mathrm{EC} / \mathrm{CO}$ at $\mathrm{T} 1$ is determined to be 0.004 , for EC in $\mu \mathrm{g} \mathrm{C} / \mathrm{m}^{3}$ and CO in $\mu \mathrm{g} / \mathrm{m}^{3}$, respectively. This result is similar to what was observed at the Baltimore supersite in the summer (Park et al., 2005b). However, the EC/CO ratio obtained at T1 differs from what Baumgardner et al. (2002), determined in Mexico City at two urban sites in 2000. The difference in the determination of EC may have contributed to this discrepancy. Baumgardner et al. (2002), used an aethalometer and a particle soot absorption photometer (PSAP) to determine EC, whereas this paper determined EC by the modified NIOSH thermal optical reflectance method. Since optical EC was also directly determined just as an aethalometer, these results were used to determine the $\mathrm{EC} / \mathrm{CO}$ ratio as well. In this case, only minor change of the result occurred. This is not surprising considering the strong correlation between Optical EC and Thermal EC (Fig. 2a). Therefore, the discrepancy is most likely caused by the different sources of EC and $\mathrm{CO}$, such factors include the type of fuel consumed by vehicles used at the sampling location, engine efficiency, or load. Since the $\mathrm{EC} / \mathrm{CO}$ value depends on multiple factors, further study could reveal more information about the difference of air masses and seasonal variations compared with other locations.

Similarly, scatter plots of OC vs. $\mathrm{NO}_{2}$ or $\mathrm{OC}$ vs. $\mathrm{O}_{3}$ do not show obvious correlations. However, stronger correlation is apparent when OC is plotted vs. the sum of oxidants $\mathrm{NO}_{2}$ and $\mathrm{O}_{3}$, or odd oxygen, $\mathrm{O}_{\mathrm{x}}$ (Fig. 12). This is because the sum of the oxidants better represents the degree of photochemical air pollution than $\mathrm{NO}_{2}$ or $\mathrm{O}_{3}$ alone. Correlation analysis suggests a predominantly secondary nature of $\mathrm{OC}$ at $\mathrm{T} 1$ during the campaign. This finding concurs with recent 
work conducted at a mountain top site within the Mexico City metropolitan area (Herndon et al., 2008). When POC and SOC are plotted separately against each of the trace gas species, a better trend is seen in some cases (see Fig. 13a and b). Although the individual scatter plots of SOC vs. $\mathrm{O}_{3}$ and $\mathrm{SOC}$ vs. $\mathrm{NO}_{2}$ do not reveal strong correlations, $\mathrm{SOC}$ vs. $\mathrm{O}_{\mathrm{x}}$, or $\mathrm{O}_{3}+\mathrm{NO}_{2}$, shows improved correlations (Fig. 13b), further confirming the contribution of secondary organic carbon at T1. For instance, correlations between POC and $\mathrm{CO}, \mathrm{NO}$, or $\mathrm{NO}_{\mathrm{x}}$ show good linearity, indicating that primary combustion-generated carbon emissions are important sources at T1 (Plaza et al., 2006). This also confirms that the estimates of POC and SOC using the EC-tracer technique are reasonable.

The ISORROPIA-II thermodynamic equilibrium model was used to assess the contribution of SOA to the increase of WSOC concentrations at T1. This analysis focuses only on three days, 27 March 2006-29 March 2006 (Hennigan et al., 2008). The box model results indicate that secondary aerosol production is responsible for the increase of WSOC. SOA is concluded to be resulted from $\mathrm{OH}$ initiated photochemical reactions from anthropogenic sources. Our results support these previous findings. Comparison with POC and SOC determined using other methodology will be useful to estimate uncertainties in each method in the future. Evaluation of contributions of the ozone and radical channels to organic aerosol formation is also of interest in future studies.

\section{Conclusions}

Elemental carbon and organic carbon were determined in near real-time by the Sunset semi-continuous OCEC field analyzer at T1 and T2 during the MILAGRO field study. High carbonaceous mass loadings were observed in the vicinity and downwind of Mexico City. Higher OC and EC were observed at $\mathrm{T} 1$ than at $\mathrm{T} 2$. The $\mathrm{EC}$ at $\mathrm{T} 2$ was particularly low, whereas $\mathrm{T} 1$ saw more fresh emissions, possibly from the nearby highways and local traffic. Diurnal variations of OC, EC, and TC were observed at both sites. The semiempirical EC-tracer method was used to derive primary and secondary organic carbons at $\mathrm{T} 1$ and $\mathrm{T} 2$. The mass loadings of EC, OC, SOC, and POC were comparable to other metropolitan areas in the world. EC and OC, including SOC and POC, were influenced by local traffic patterns at $\mathrm{T} 1$ and $\mathrm{T} 2$, as well as meteorological conditions. Characteristics of OC, EC, SOC, and POC during T1 to T2 transport possible and likely days differed from transport unlikely days. The stronger similarities of SOC and POC between T1 and $\mathrm{T} 2$ under transport favorable conditions indicate that particle transport occurred. EC, OC, SOC and POC were investigated with respect to trace gas pollutants measured at $\mathrm{T} 1$. Strong correlations of EC and POC vs. CO, NO, and $\mathrm{NO}_{\mathrm{x}}$ respectively were observed, indicating primary influence of local traffic emissions. The EC/CO value was determined as
0.004 at T1. Correlations were also seen between OC and SOC vs. the odd oxygen or the sum of $\mathrm{O}_{3}$ and $\mathrm{NO}_{2}$, further confirming the secondary nature of carbons observed at $\mathrm{T} 1$. Comparisons between the AMS determined HOA, OOA, and OM vs. the Sunset POA, SOA, and OA are in good agreement. This further validates that the usefulness of the simpler EC-tracer method in estimating SOA and POA. Future work should be done to investigate the uncertainties among different methods to determine SOA (SOC) and POA (POC) for longer periods of time and for wide range of locations.

Acknowledgements. The work was supported by the Office of Science (BER), US Department of Energy (USDOE), under the auspices of the Atmospheric Science Program, under Contract DE-AC05-76RL01830 at the Pacific Northwest National Laboratory (PNNL). PNNL is operated for the USDOE by Battelle. Meteorological data from T1 were provided by Richard Coulter at Argonne National Laboratory; and meteorological data from T2 by Christopher Doran, William Shaw and Mikhial Pekour at PNNL. Trace gas data from T1 were provided by the research groups of Gregory Huey of the Georgia Institute of Technology and Ronald Cohen of the University of California, Berkeley. The authors thank Carl Berkowitz and Jerome Fast of PNNL for useful discussions about emission sources. The authors also thank Timothy Onasch at Aerodyne Research, Inc., for his support in the AMS data analysis, Manjula Canagaratna for her comments in the AMS POA and OOA analysis, and Lizabeth Alexander for operating the AMS.

Edited by: J. Gaffney

\section{References}

Aiken, A. C., Decarlo, P. F., Kroll, J. H., et al.: O/C and OM/OC ratios of primary, secondary, and ambient organic aerosols with high-resolution time-of-flight aerosol mass spectrometry, Environ. Sci. Technol., 42(12), 4478-4485, 2008.

Allen, G. A., Lawrence, J., and Koutrakis, P.: Field validation of a semi-continuous method for aerosol black carbon (aethalometer) and temporal patterns of summertime hourly black carbon measurements in southwestern PA, Atmos. Environ., 33(5), 817-823, 1999.

Bauer, J. J., Yu, X.-Y., Laulainen, N. S., et al.: Characterization of the Sunset Semi-Continuous Carbon Aerosol Analyzer, J. Air Waste Manage., 59(7), 826-833, 2009.

Baumgardner, D., Raga, G., Peralta, O., et al.: Diagnosing black carbon trends in large urban areas using carbon monoxide measurements, J. Geophys. Res.-Atmos., 107(D21), 8342, doi:10.1029/2001JD000626, 2002.

Birch, M. E.: Analysis of carbonaceous aerosols: interlaboratory comparison, Analyst, 123(5), 851-857, 1998.

Cabada, J. C., Pandis, S. N., Subramanian, R., et al.: Estimating the secondary organic aerosol contribution to $\mathrm{PM}_{2.5}$ using the EC tracer method, Aerosol Sci. Tech., 38, 140-155, 2004.

Cachier, H., Bremond, M. P., and Buatmenard, P.: Thermal Separation of soot carbon, Aerosol Sci. Tech., 10(2), 358-364, 1989.

Canagaratna, M. R., Jayne, J. T., Jimenez, J. L., et al.: Chemical and microphysical characterization of ambient aerosols with 
the aerodyne aerosol mass spectrometer, Mass Spectrom. Rev., 26(2), 185-222, 2007.

Cao, J. J., Lee, S. C., Ho, K. F., et al.: Characteristics of carbonaceous aerosol in Pearl River Delta Region, China during 2001 winter period, Atmos. Environ., 37(11), 1451-1460, 2003.

Castro, L. M., Pio, C. A., Harrison, R. M., et al.: Carbonaceous aerosol in urban and rural European atmospheres: estimation of secondary organic carbon concentrations, Atmos. Environ., 33(17), 2771-2781, 1999.

Chen, G., Huey, L. G., Trainer, M., et al.: An investigation of the chemistry of ship emission plumes during ITCT 2002, J. Geophys. Res.-Atmos., doi:10.1029/2004JD005236, 2005.

Chen, L. W. A., Doddridge, B. G., Dickerson, R. R., et al.: Seasonal variations in elemental carbon aerosol, carbon monoxide and sulfur dioxide: Implications for sources, Geophys. Res. Lett., 28(9), 1711-1714, 2001.

Chow, J. C., Watson, J. G., Fujita, E. M., et al.: Temporal and Spatial Variations of $\operatorname{Pm}(2.5)$ and $\operatorname{Pm}(10)$ Aerosol in the Southern California Air-Quality Study, Atmos. Environ., 28(12), 20612080, 1994.

Chow, J. C., Watson, J. G., Crow, D., et al.: Comparison of IMPROVE and NIOSH carbon measurements, Aerosol Sci. Tech., 34(1), 23-34, 2001.

Chow, J. C., Watson, J. G., Edgerton, S. A., et al.: Chemical composition of PM2.5 and PM10 in Mexico City during winter 1997, Sci. Total Environ., 287(3), 177-201, 2002.

Chow, J. C., Watson, J. G., Lowenthal, D. H., et al.: Particulate carbon measurements in California's San Joaquin Valley, Chemosphere, 62(3), 337-348, 2006.

Chu, S. H.: Stable estimate of primary OC/EC ratios in the EC tracer method, Atmos. Environ., 39(8), 1383-1392, 2005.

Cornbleet, P. J., and Gochman, N.: Incorrect Least-Squares Regression Coefficients in Method-Comparison Analysis Clin. Chem., 25(3), 432-438, 1979.

Dan, M., Zhuang, G. S., Li, X. X., et al.: The characteristics of carbonaceous species and their sources in $\mathrm{PM}_{2.5}$ in Beijing, Atmos. Environ., 38(21), 3443-3452, 2004.

de Gouw, J. A., Welsh-Bon, D., Warneke, C., Kuster, W. C., Alexander, L., Baker, A. K., Beyersdorf, A. J., Blake, D. R., Canagaratna, M., Celada, A. T., Huey, L. G., Junkermann, W., Onasch, T. B., Salcido, A., Sjostedt, S. J., Sullivan, A. P., Tanner, D. J., Vargas, O., Weber, R. J., Worsnop, D. R., Yu, X. Y., and Zaveri, R.: Emission and chemistry of organic carbon in the gas and aerosol phase at a sub-urban site near Mexico City in March 2006 during the MILAGRO study, Atmos. Chem. Phys., 9, 3425-3442, 2009,

http://www.atmos-chem-phys.net/9/3425/2009/.

Doran, J. C., Barnard, J. C., Arnott, W. P., Cary, R., Coulter, R., Fast, J. D., Kassianov, E. I., Kleinman, L., Laulainen, N. S., Martin, T., Paredes-Miranda, G., Pekour, M. S., Shaw, W. J., Smith, D. F., Springston, S. R., and Yu, X.-Y.: The T1-T2 study: evolution of aerosol properties downwind of Mexico City, Atmos. Chem. Phys., 7, 1585-1598, 2007,

http://www.atmos-chem-phys.net/7/1585/2007/.

Doran, J. C., Fast, J. D., Barnard, J. C., Laskin, A., Desyaterik, Y., and Gilles, M. K.: Applications of lagrangian dispersion modeling to the analysis of changes in the specific absorption of elemental carbon, Atmos. Chem. Phys., 8, 1377-1389, 2008, http://www.atmos-chem-phys.net/8/1377/2008/.
Drewnick, F., Hings, S. S., DeCarlo, P., et al.: A new time-of-flight aerosol mass spectrometer (TOF-AMS) - Instrument description and first field deployment, Aerosol Sci. Tech., 39(7), 637-658, 2005.

Duan, F. K., He, K. B., Ma, Y. L., et al.: Characteristics of carbonaceous aerosols in Beijing, China, Chemosphere, 60(3), 355-364, 2005.

Fast, J. D., de Foy, B., Acevedo Rosas, F., Caetano, E., Carmichael, G., Emmons, L., McKenna, D., Mena, M., Skamarock, W., Tie, X., Coulter, R. L., Barnard, J. C., Wiedinmyer, C., and Madronich, S.: A meteorological overview of the MILAGRO field campaigns, Atmos. Chem. Phys., 7, 2233-2257, 2007, http://www.atmos-chem-phys.net/7/2233/2007/.

Fehsenfeld, F. C., Dickerson, R. R., Hubler, G., et al.: A groundbased intercomparison of $\mathrm{NO}, \mathrm{No}_{\mathrm{x}}$, and $\mathrm{No}_{\mathrm{y}}$ measurement techniques, J. Geophys. Res.-Atmos., 92(D12), 14710-14722, 1987.

Feng, J. L., Hu, M., Chan, C. K., et al.: A comparative study of the organic matter in $\mathrm{PM}_{2.5}$ from three Chinese megacities in three different climatic zones, Atmos. Environ., 40(21), 3983-3994, 2006.

Gelencser, A., May, B., Simpson, D., et al.: Source apportionment of $\mathrm{PM}_{2.5}$ organic aerosol over Europe: Primary/secondary, natural/anthropogenic, and fossil/biogenic origin, J. Geophys. Res.Atmos., 112(D23), doi:10.1029/2006JD008094, 2007.

Harley, R. A., Marr, L. C., Lehner, J. K., et al.: Changes in motor vehicle emissions on diurnal to decadal time scales and effects on atmospheric composition, Environ. Sci. Technol., 39(14), 53565362, 2005.

Hennigan, C. J., Sullivan, A. P., Fountoukis, C. I., Nenes, A., Hecobian, A., Vargas, O., Peltier, R. E., Case Hanks, A. T., Huey, L. G., Lefer, B. L., Russell, A. G., and Weber, R. J.: On the volatility and production mechanisms of newly formed nitrate and water soluble organic aerosol in Mexico City, Atmos. Chem. Phys., 8, 3761-3768, 2008,

http://www.atmos-chem-phys.net/8/3761/2008/.

Herndon, S. C., Onasch, T. B., Wood, E. C., et al.: Correlation of secondary organic aerosol with odd oxygen in Mexico City, Geophys. Res. Lett., 35(15), L15804, doi:10.1029/2008GL034058, 2008.

Hildemann, L. M., Rogge, W. F., Cass, G. R., et al.: Contribution of primary aerosol emissions from vegetation-derived sources to fine particle concentrations in Los Angeles, J. Geophys. Res.Atmos., 101(D14), 19541-19549, 1996.

Ho, K. F., Lee, S. C., Yu, J. C., et al.: Carbonaceous characteristics of atmospheric particulate matter in Hong Kong, Sci. Total Environ., 300(1-3), 59-67, 2002.

Jeong, C. H., Hopke, P. K., Kim, E., et al.:, The comparison between thermal-optical transmittance elemental carbon and Aethalometer black carbon measured at multiple monitoring sites, Atmos. Environ., 38(31), 5193-5204, 2004.

Lanz, V. A., Alfarra, M. R., Baltensperger, U., Buchmann, B., Hueglin, C., and Prévôt, A. S. H.: Source apportionment of submicron organic aerosols at an urban site by factor analytical modelling of aerosol mass spectra, Atmos. Chem. Phys., 7, 15031522, 2007, http://www.atmos-chem-phys.net/7/1503/2007/.

Lim, H. J. and Turpin, B. J.: Origins of primary and secondary organic aerosol in Atlanta: Results' of time-resolved measurements during the Atlanta supersite experiment, Environ. Sci. 
Technol., 36(21), 4489-4496, 2002.

Lonati, G., Ozgen, S., and Giugliano, M.: Primary and secondary carbonaceous species in $\mathrm{PM}_{2.5}$ samples in Milan (Italy), Atmos. Environ., 41(22), 4599-4610, 2007.

Martin, R.: General Deming Regression for Estimating Systematic Bias and Its Confidence Interval in Method-Comparison Studies, Clin. Chem., 46(1), 100-104, 2000.

Nunnermacker, L. J., Imre, D., Daum, P. H., et al.: Characterization of the Nashville urban plume on July 3 and July 18, 1995, J. Geophys. Res.-Atmos., 103(D21), 28129-28148, 1998.

Pandis, S. N., Harley, R. A., Cass, G. R., et al.: Secondary Organic Aerosol Formation and Transport, Atmos. Environ. AGen., 26(13), 2269-2282, 1992.

Park, S. S., Bae, M. S., Schauer, J. J., et al.: Evaluation of the TMO and TOT methods for OC and EC measurements and their characteristics in $\mathrm{PM}_{2.5}$ at an urban site of Korea during ACE-Asia, Atmos. Environ., 39(28), 5101-5112, 2005a.

Park, S. S., Harrison, D., Pancras, J. P., et al.: Highly timeresolved organic and elemental carbon measurements at the Baltimore Supersite in 2002, J. Geophys. Res.-Atmos., 110(D7), doi:10.1029/2004JD004610, 2005b.

Patashnick, H. and Rupprecht, E. G.: Continous PM-10 measurements using the tapered element oscillating microbalance, J. Air Waste Manage., 41(8), 1079-1083, 1991.

Plaza, J., Gomez-Moreno, F. J., Nunez, L., et al.: Estimation of secondary organic aerosol formation from semicontinuous OCEC measurements in a Madrid suburban area, Atmos. Environ., 40(6), 1134-1147, 2006.

Querol, X., Pey, J., Minguillón, M. C., Pérez, N., Alastuey, A., Viana, M., Moreno, T., Bernabé, R. M., Blanco, S., Cárdenas, B., Vega, E., Sosa, G., Escalona, S., Ruiz, H., and Artíñano, B.: PM speciation and sources in Mexico during the MILAGRO-2006 Campaign, Atmos. Chem. Phys., 8, 111-128, 2008,

http://www.atmos-chem-phys.net/8/111/2008/.

Russell, M., and Allen, D. T.: Seasonal and spatial trends in primary and secondary organic carbon concentrations in southeast Texas, Atmos. Environ., 38(20), 3225-3239, 2004.

Salma, I., Chi, X. G., and Maenhaut, W.: Elemental and organic carbon in urban canyon and background environments in Budapest, Hungary, Atmos. Environ., 38(1), 27-36, 2004.

Saylor, R. D., Edgerton, E. S., and Hartsell, B. E.: Linear regression techniques for use in the EC tracer method of secondary organic aerosol estimation, Atmos. Environ., 40(39), 7546-7556, 2006.

Schauer, J. J., Rogge, W. F., Hildemann, L. M., et al.: Source apportionment of airborne particulate matter using organic compounds as tracers, Atmos. Environ., 30(22), 3837-3855, 1996.

Schauer, J. J., Fraser, M. P., Cass, G. R., et al.: Source reconciliation of atmospheric gas-phase and particle-phase pollutants during a severe photochemical smog episode, Environ. Sci. Technol., 36(17), 3806-3814, 2002.

Schauer, J. J., Mader, B. T., Deminter, J. T., et al.: ACE-Asia intercomparison of a thermal-optical method for the determination of particle-phase organic and elemental carbon, Environ. Sci. Technol., 37(5), 993-1001, 2003.

Schichtel, B. A., Malm, W. C., Bench, G., et al.: Fossil and contemporary fine particulate carbon fractions at 12 rural and urban sites in the United States, J. Geophys. Res.-Atmos., 113(D2), doi:10.1029/2007JD008605, 2008.

Shaw, W. J., Pekour, M. S., Coulter, R. L., Martin, T. J., and Walters,
J. T.: The daytime mixing layer observed by radiosonde, profiler, and lidar during MILAGRO, Atmos. Chem. Phys. Discuss., 7, 15025-15065, 2007, http://www.atmos-chem-phys-discuss.net/7/15025/2007/.

Stone, E. A., Snyder, D. C., Sheesley, R. J., Sullivan, A. P., Weber, R. J., and Schauer, J. J.: Source apportionment of fine organic aerosol in Mexico City during the MILAGRO experiment 2006, Atmos. Chem. Phys., 8, 1249-1259, 2008, http://www.atmos-chem-phys.net/8/1249/2008/.

Strader, R., Lurmann, F., and Pandis, S. N.: Evaluation of secondary organic aerosol formation in winter, Atmos. Environ., 33(29), 4849-4863, 1999.

Sullivan, A. P., Peltier, R. E., Brock, C. A., et al.: Airborne measurements of carbonaceous aerosol soluble in water over northeastern United States: Method development and an investigation into water-soluble organic carbon sources, J. Geophys. Res.-Atmos., 111(D23), doi:10.1029/2006JD007072, 2006.

Takegawa, N., Miyakawa, T., Kondo, Y., et al.: Seasonal and diurnal variations of submicron organic aerosol in Tokyo observed using the Aerodyne aerosol mass spectrometer, J. Geophys. Res.Atmos., 111(D11), doi:10.1029/2005JD006515, 2006.

Turpin, B. J. and Huntzicker, J. J.: Secondary formation of organic aerosol in the Los-Angeles basin - A descriptive analysis of organic and elemental carbon concentrations, Atmos. Environ. AGen., 25(2), 207-215, 1991.

Turpin, B. J., Huntzicker, J. J., Larson, S. M., et al.: Los-Angeles summer midday particulate carbon - primary and secondary aerosol, Environ. Sci. Technol., 25(10), 1788-1793, 1991.

Turpin, B. J. and Huntzicker, J. J.: Identification of Secondary Organic Aerosol Episodes and Quantitation of Primary and Secondary Organic Aerosol Concentrations During Scaqs, Atmos. Environ., 29(23), 3527-3544, 1995.

Turpin, B. J., Saxena, P., and Andrews, E.: Measuring and simulating particulate organics in the atmosphere: problems and prospects, Atmos. Environ., 34(18), 2983-3013, 2000.

Ulbrich, I. M., Canagaratna, M. R., Zhang, Q., Worsnop, D. R., and Jimenez, J. L.: Interpretation of organic components from Positive Matrix Factorization of aerosol mass spectrometric data, Atmos. Chem. Phys., 9, 2891-2918, 2009, http://www.atmos-chem-phys.net/9/2891/2009/.

Viana, M., Maenhaut, W., ten Brink, H. M., et al.: Comparative analysis of organic and elemental carbon concentrations in carbonaceous aerosols in three European cities, Atmos. Environ., 41(28), 5972-5983, 2007.

Wang, T., Wong, C. H., Cheung, T. F., et al.: Relationships of trace gases and aerosols and the emission characteristics at Lin'an, a rural site in eastern China, during spring 2001, J. Geophys. Res.Atmos., 109(D19), doi:10.1029/2003JD004119, 2004.

Watson, J. G. and Chow, J. C.: A wintertime $\mathrm{PM}_{2.5}$ episode at the fresno, CA, supersite, Atmos. Environ., 36(3), 465-475, 2002.

Yu, J. H., Chen, T., Guinot, B., et al.: Characteristics of carbonaceous particles in Beijing during winter and summer 2003, Adv. Atmos. Sci., 23(3), 468-473, 2006.

Yu, J. Z., Tung, J. W. T., Wu, A. W. M., et al.: Abundance and seasonal characteristics of elemental and organic carbon in Hong Kong $\mathrm{PM}_{10}$, Atmos. Environ., 38(10), 1511-1521, 2004.

Yu, S., Bhave, P. V., Dennis, R. L., et al.: Seasonal and regional variations of primary and secondary organic aerosols over the Continental United States: Semi-empirical estimates and model 
evaluation, Environ. Sci. Technol., 41(13), 4690-4697, 2007.

Yu, S. C., Dennis, R. L., Bhave, P. V., et al.: Primary and secondary organic aerosols over the United States: estimates on the basis of observed organic carbon (OC) and elemental carbon (EC), and air quality modeled primary OC/EC ratios, Atmos. Environ., 38(31), 5257-5268, 2004.
Yuan, Z. B., Yu, J. Z., Lau, A. K. H., Louie, P. K. K., and Fung, J. C. H.: Application of positive matrix factorization in estimating aerosol secondary organic carbon in Hong Kong and its relationship with secondary sulfate, Atmos. Chem. Phys., 6, 25-34, 2006,

http://www.atmos-chem-phys.net/6/25/2006/. 